\title{
Short Sale Constraints, Heterogeneous Interpretations, and Asymmetric Price Reactions to Earnings Announcements*
}

\author{
Eric C. Chang \\ Faculty of Business and Economics \\ The University of Hong Kong \\ K K Leung Building \\ Pokfulam Road, Hong Kong \\ ecchang@business.hku.hk \\ Jianguo $\mathrm{Xu}$ \\ McGill University \\ 1001 Sherbrooke St. W \\ Montreal, Quebec H3A 1G5, Canada \\ jianguo.xu@mcgill.ca \\ Liu Zheng \\ School of Business \\ University of Hong Kong \\ Meng Wah Complex \\ Pokfulam Road, Hong Kong \\ lzheng@business.hku.hk
}

\footnotetext{
* We would like to thank Kalok Chan, Jie Gan, Oliver Kim, Amy H.L. Lau, Tse-Chun Lin, Laura Liu, Chul W. Park, Mort Pincus, Charles Shi, Siew Hong Teoh, John Wei, Fan Yu, Lu Zheng, and seminar participants at the University of California at Irvine, Hong Kong University of Science and Technology, and University of Hong Kong for helpful comments and suggestions. Eric C. Chang gratefully acknowledges the funding support from the Research Grant Council of the Hong Kong Special Admistrative Region, China (HKU 7403/06H). Liu Zheng gratefully acknowledges the funding support from the Research Grant Council of the Hong Kong Special Admistrative Region, China (HKU 7551/08H). All errors are our own.
} 


\title{
Short Sale Constraints, Heterogeneous Interpretations, and Asymmetric Price
}

\section{Reactions to Earnings Announcements}

\begin{abstract}
We investigate the effects of heterogeneous interpretations on price reactions to earnings announcements. We find that when investors interpret earnings news homogenously, price reactions are stronger to bad news. However, when interpretations of earnings news become more heterogeneous, price reactions become stronger to good news. This pattern is more pronounced when the short sale constraints are more binding. These findings support the notion that, under short sale constraints, price reactions to public information reflect the selective registration of more optimistic opinions rather than the average opinion of all investors. This study contributes to the accounting literature on the impact of heterogeneous interpretations on price reactions to earnings announcements. Our evidence on the significant interplay between the price and volume reactions to earnings announcements also adds to the resurgence of interest in connecting trading activity to prices.
\end{abstract}

JEL Classification: G12, G14, M41

Keywords: Heterogeneous beliefs, short sale constraints, asymmetric price reactions. 


\section{Introduction}

Earnings announcements are among the most important information events by which firms disclose information to the market. Accounting research provides extensive evidence that earnings announcements convey important information for security valuation. It has also been well recognized that deriving the valuation implications of earnings signals is complicated, even for sophisticated financial analysts. This complexity leaves ample room for disagreement among investors in interpreting earnings signals. The effect of heterogeneous interpretations of earnings signals on the price reactions to earnings announcements has not received much attention. The lack of attention probably reflects the traditional view that, although disagreement on the public information generates trading activity, ${ }^{1}$ these trades are idiosyncratic and hence offset the effects of one another, thus having no consequences for average prices (Hong and Stein 2007). Building on the insights of recent theoretical literature on the pricing effects of short sale constraints, this study examines the effect of heterogeneous interpretations of earnings signals on the price reactions to earning announcements.

Two recent empirical studies have investigated the effects of short sale constraints on the price reactions to earnings announcements. Reed (2007) shows that stocks for which short selling is particularly costly have larger price reactions to earnings announcements, especially to bad news. He suggests that this evidence confirms Diamond and Verrechia's (1987) hypothesis that short sale constraints reduce the speed with which prices adjust to private (especially negative) information. Berkman et al. (2009) document that stocks with a greater difference of opinion prior to earnings announcements earn lower returns around these announcements, and this pattern is more salient within the subsample of stocks that are more difficult for investors to sell

\footnotetext{
${ }^{1}$ For example, Kandel and Pearson (1995) and Bamber et al. (1999), among others, examine the effects of heterogeneous interpretations of earnings signals in explaining trading volume around earnings announcements.
} 
short. Their evidence suggests that overvaluation exists under short sale constraints, which is consistent with Miller's (1977) overpricing hypothesis, and earnings announcements narrow the differences of opinion, hence reducing overvaluation.

The focus of Reed (2007) and Berkman et al. (2009) is on the effect of earnings announcements in enhancing agreement by mitigating the information asymmetry or differences of opinion that exist prior to the announcement event. Reed (2007) regards earnings as private information until a public announcement is made. Berkman et al. (2009) argue that although differences of opinion among investors about stock value may not be completely eliminated after earnings announcements, they are reduced. Neither Reed (2007) nor Berkman et al. (2009) consider price reactions to earnings announcements conditional on the degree of heterogeneity in the interpretations of the earnings news. In this study, we extend the existing analysis by incorporating the effect of heterogeneous interpretations of earnings news. Interestingly, we find that the earlier conclusion is reversed when significant heterogeneous interpretation is present.

The literature on heterogeneous interpretations of information and the literature on short sale constraints have largely evolved separately. ${ }^{2}$ The literature on heterogeneous interpretations focuses on the possibility that public information may trigger different interpretations, which leads to different opinions and stimulates trading. The extensive studies on short sale constraints assume that differences of opinion exist and are reduced over time; as a result, overvaluation is corrected over time. A recent study, Xu (2007), joins these two lines of research and analyzes how heterogeneous interpretations of public signals contribute to overvaluation. Xu (2007) extends Miller's (1977) intuition to the setting of stock price reactions to public announcements.

\footnotetext{
${ }^{2}$ Differences of opinion, a concept closely related to heterogeneous interpretation, are always assumed in the literature on short sale constraints. However, the literature on short sale constraints has not paid enough attention to how differences of opinion arise and, more importantly, to the pricing effects when differences of opinions arise. One exception is $\mathrm{Xu}$ (2007).
} 
One key prediction of his study is that heterogeneous interpretations among investors, when coupled with short sale constraints, do not offset the effects of one another. Instead, they affect equilibrium prices. In particular, $\mathrm{Xu}$ (2007) predicts that the selective registration of more optimistic opinions under short sale constraints implies stronger price reactions to good news than to bad news, and this asymmetry increases with the degree of interpretation heterogeneity and short sale constraints.

Following the literature, we employ institutional ownership as an inverse proxy for short sale constraints and abnormal trading volume around earnings announcements as a proxy for heterogeneous interpretations of earnings news. We find that price reactions are stronger to bad news when investors interpret earnings news homogenously, a result that is consistent with Reed (2007) and offers support for Diamond and Verrecchia (1987). However, when interpretations become more heterogeneous, price reactions become stronger to good news. This pattern is more pronounced when the short sale constraints are more binding. Our findings support the notion that, in the presence of short sale constraints, the heterogeneous interpretations of earnings announcements have important implications for the price reactions to earnings announcements, which is consistent with the predictions based on the selective registration of more optimistic opinions (Miller 1977; Xu 2007).

To further explore the implications of the heterogeneous interpretations of earnings news on price reactions to the earnings announcements, we conduct a similar test to that in Berkman et al. (2009). We consider first separately and then jointly (1) pre-announcement opinion divergence and (2) opinion divergence triggered by heterogeneous interpretations of the earnings announcements. Similar to Berkman et al. (2009), we find that when stocks are sorted on preannouncement opinion divergence alone, portfolios with greater differences of opinion prior to 
announcements earn lower returns around earnings announcements. However, when we sort stocks on opinion divergence triggered by heterogeneous interpretations of earnings announcements, we find that stocks with more heterogeneous interpretations earn significantly higher returns. The latter pattern is consistent with the hypothesis of selective registration of optimistic interpretations of earnings news. Finally, we double sort firms by both types of divergence. We find that stocks with a large degree of pre-announcement opinion divergence, but relatively homogeneous interpretations of earnings news, earn the lowest abnormal returns around earnings announcements, whereas those with a small degree of pre-announcement opinion divergence, but high heterogeneous interpretations of earnings news, earn the highest abnormal returns around earnings announcements. The results of this joint test suggest that, considering disagreement on earnings implications, earnings announcements may not always narrow opinion divergence and correct overvaluation. This paper suggests that the pattern of stock price reaction to earnings also reflects selective registration of more optimistic opinions upon earnings announcements. The finding complements that in Berkman et al. (2009) in illuminating the implications of short sale constraints on stock price reactions around earnings announcements.

Finally, we explore whether short sale constraints and the heterogeneous interpretations of earnings announcements are associated with the pattern of post-earnings-announcement drift (PEAD). We find that the patterns observed in the drift window bear some resemblance to those observed over the announcement window. If one takes the view of delayed response as a cause of PEAD, then these patterns are intuitively appealing. Our findings suggest that short sale constraints and heterogeneous interpretations of the announced earnings may also play a role in asymmetric PEAD patterns. 
This paper makes several contributions to accounting literature. First, it contributes to the body of accounting research that investigates price and volume reactions to earnings announcements. Our empirical evidence suggests a significant interaction between the price and volume reactions to earnings announcements. It has been well established that heterogeneous interpretations are an important stimulus for trading around earnings announcements. To the extent that the abnormal trading volume captures heterogeneous interpretations of earnings news, our evidence suggests that heterogeneous interpretations have important implications for price reactions to earnings announcements, rather than being cancelled out in the price aggregation process. ${ }^{3}$ Second, this paper contributes to accounting research that investigates asymmetric price reactions to earnings announcements. Our evidence shows that the asymmetric price reactions to good news and bad news vary in a systematic way with the degree of heterogeneous interpretations and short sale constraints. Basu (1997) hypothesizes stronger price reactions to positive than to negative earnings news due to conservative accounting principle. Our study offers new insights on the asymmetric price reactions to earnings news. Third, this paper complements Berkman et al. (2009) on the implications of short sale constraints on stock returns around earnings announcements. ${ }^{4}$

This paper also contributes to finance literature. First, this study joins the resurgence of interest in finance that connects trading activity to prices through the disagreement model. Hong

\footnotetext{
${ }^{3}$ As discussed later, although trading volume can be explained by many factors other than heterogeneous interpretation, those factors do not play roles in explaining the asymmetric price reaction pattern documented in this paper. Hence, they do not nullify the effects of differences of opinion.

${ }^{4}$ Similar to Berkman et al. (2009), Mashruwala et al. (2009) also examine the effect of ex-ante disagreement (i.e. opinion divergence prior to earnings announcements) and short sale constraints on returns around earnings announcements. They find that absolute return to bad earnings news is greater than absolute return to good earnings news, and the asymmetrically larger price reaction to bad news is driven by the very act of missing the consensus earnings forecasts. They argue that their results help explain the "torpedo effect" of Skinner and Sloan (2002). However, their results seem to contradict prior findings. Hand (2002) points out that the asymmetry proposed by Skinner and Sloan (2002) exists only for extreme news with price-scaled earnings surprises greater than $0.7 \%$, while more than $80 \%$ of earnings surprises in our sample fall into the interval of $[-0.1 \%, 0.1 \%]$
} 
and Stein (2007) assert that disagreement models uniquely hold the promise of being able to deliver a comprehensive joint account of stock prices and trading volume. Second, most existing evidence relies on lower future returns in stocks with more dispersed beliefs and/or higher short selling costs to backwardly infer ex ante overpricing. ${ }^{5}$ Examining the immediate asymmetric price reactions to good news versus bad news conditional on the degree of heterogeneous interpretation and short sale constraints presents a new perspective to test the idea of selective registration of optimistic opinion pioneered by Miller (1977). As the price impact that short-sale constraints may have on stocks has important policy implications, we expect that our findings to provide useful insights for both policy makers and academic researchers.

The remainder of the paper is structured as follows. Section 2 reviews the related literature and develops our hypothesis. Section 3 discusses our research design. Section 4 describes the data and empirical results. Section 5 provides further analysis, and Section 6 concludes.

\section{Literature review and hypothesis development}

Earnings announcements are among the most important information events by which firms disclose information to the market. Accounting research provides extensive evidence that earnings announcements convey important information for security valuation. Empirical evidence suggests that earnings announcements generate both, yet differential, abnormal price and volume reactions. For example, Bamber and Cheon (1995) provide empirical evidence that earnings announcements sometimes generate heavy trading but minimal price change, and vice

\footnotetext{
${ }^{5}$ See, for example, Figlewski (1981), Chen et al. (2002), Diether et al. (2002), Jones and Lamont (2002), Asquith, et al. (2005), Nagel (2005), and Boehme et al. (2006).
} 
versa. ${ }^{6}$ Beaver (1968) asserts that an important distinction between the price and volume reaction is that the former reflects the aggregate change in the market's average expectation of the company's prospects attributable to the signal, whereas the latter reflects the heterogeneity of the change in the expectations of individual investors.

One of the main sources of differential belief revisions is differential interpretations of public announcements (e.g., Harris and Raviv 1993; Kandel and Pearson 1995); that is, despite sharing common information, individuals may disagree on the meaning of the information. This notion of differential interpretations has a long history, dating back to Bachelier's (1900) seminal thesis on price fluctuations. In the earnings announcement setting, deriving the valuation implications of earnings signals is complicated, even for sophisticated financial analysts. This complexity leaves ample room for disagreement among investors in interpreting earnings signals (Zhang 2006; Francis et al. 2007; Lu 2004). ${ }^{7}$ Kandel and Pearson (1995) provide compelling evidence that trading volume is higher around earnings announcements, even without price changes, and suggest that the differential interpretation of earnings signals is a strong candidate for explaining the phenomenon. Bamber et al. (1999) provide additional support for the idea that differential interpretations are an important stimulus for speculative trading around earnings announcements. A growing body of accounting research suggests that investors do not interpret earnings announcements in a similar manner as the announcements spur the generation of private information and the differences in investors' private information explain the trading volume that is not associated with price changes (Kim and Verrecchia 1997; Barron et al. 2002; Hope et al. 2009).

\footnotetext{
${ }^{6}$ Prior studies (e.g., Courtenay et al., 1989) have also provided evidence of differential price and volume reactions to information produced during the enactment of new legislations.

${ }^{7} \mathrm{Lu}$ (2004) provides several pieces of anecdotal evidence that suggest it is challenging for investors, even the most sophisticated, to gauge the valuation implications of newly released earnings information.
} 
Despite the efforts made to better understand the relationship between heterogeneous interpretations of earnings numbers and trading volume around public announcements, the question of whether heterogeneous interpretations affect price reactions to public announcements has not received much attention. ${ }^{8}$ Conventional wisdom suggests that differential belief revisions should have no effect on price reactions to public announcements, because the different opinions of investors are expected to "cancel out" in the aggregation process of equilibrium price determination (Lintner 1969; Bamber and Cheon 1995). However, there is an ongoing debate about whether prices do indeed always reflect the average unbiased opinion.

The finance literature has evolved in showing how equilibrium asset prices change in the presence of heterogeneous beliefs and market frictions. Lintner (1969), for example, shows that heterogeneous beliefs about asset value alone do not change capital market equilibrium. Miller (1977) considers the combined effects of short sale constraints and differences of opinion on stock prices and suggests that when short selling is costly, some pessimistic opinions are kept out of the market so that prices tend to reflect more optimistic opinions, leading to upward biases in prices. Many studies have further extended Miller’s (1977) overpricing hypothesis. Jarrow (1980) and Figlewski (1981) were among the first to model Miller’s (1977) idea rigorously, and more recent developments include those made by Varian (1989), Harris and Raviv (1993), Morris

\footnotetext{
${ }^{8}$ One exception is Rees and Thomas (2010), who examine the effects of changes in dispersion of investor beliefs on stock prices during earnings announcements. They find that the 3-day price reactions to earnings announcements are negatively associated with changes in dispersion of individual analysts' forecasts, which they argue is consistent with the cost of capital hypothesis and inconsistent with Miller's (1977) overpricing hypothesis. As discussed below, our paper differs from Rees and Thomas (2010), as we focus on the asymmetric price reactions to good news versus bad news using recent theoretical developments in the short sale constraints literature. In addition, Rees and Thomas (2010) do not condition their tests on short sale constraints. In fact, the adoption of the changes of dispersion of analysts' forecasts before and after earnings announcements as the key proxy for the change of opinion divergence may bias against the overpricing hypothesis, because most of the small firms with only one or two analysts following (which would arguably be more subject to short sale constraints) would have to be dropped from the sample.
} 
(1996), Scheinkman and Xiong (2003), and Hong et al. (2006). ${ }^{9}$

Diamond and Verrecchia (1987) hold a different view. In a rational expectations framework with information asymmetry, they argue that rational investors take the possible existence of hidden negative information into consideration when trading. As a result, short sale constraints do not bias asset prices upwards, but do affect the adjustment speed of prices to private information. In Diamond and Verrecchia (1987), uninformed investors observe only public information and informed investors all observe identical private information; thus, there are no heterogeneous interpretations.

More recently, Xu (2007) connects the short sale constraints literature with the literature on heterogeneous interpretations of public information and extends Miller's intuition into the setting of the price reactions to public announcements. This model predicts that, rather than being “cancelled out," heterogeneous interpretations of the public signal among individual investors, coupled with short sale constraints, affect equilibrium prices. Given that short sale constraints are, in general, binding and that heterogeneous interpretations may exist in certain circumstances, this prediction has important implications for the price reactions to earnings announcements. $^{10}$

Xu (2007) assumes that investors who are prohibited from short selling initially agree on the value of a stock, but disagree on the precision of the public signal they have observed. "Highprecision” investors think that the signal's precision is higher than "low precision” investors do.

\footnotetext{
${ }^{9}$ Empirical studies on the effects of short sale constraints on overvaluation include, but are not limited to, Figlewski (1981), Chen et al. (2002), Diether et al. (2002), Nagel (2005), Boehme et al. (2006), and Chang et al. (2007).

${ }^{10}$ Xu’s (2007) argument applies to public announcements in general. Unlike earnings announcements, many news events are discretionary, and the differential incentives to disclose good versus bad news render the valuation implications more difficult to assess. In addition, measures of market expectations are generally lacking. Xu (2007) also picks the earnings announcement setting to conduct some preliminary empirical tests on the asymmetry of price reactions to good versus bad news, but he does not empirically examine how heterogeneous interpretations and short sale constraints affect asymmetry.
} 
As a result, "high-precision" investors react more to the news signals than the "low-precision" investors do.

Upon receiving a piece of good news, "high-precision" investors, who react more to the news, tend to have higher asset valuation than the "low-precision" investors, who react less. Conversely, upon receiving a piece of bad news, "low-precision” investors, who react less to the news, tend to have higher asset valuation than the "high-precision" investors who react more. Coupled with Miller's intuition that short sale constraints prevent pessimistic opinions from being reflected in prices, Xu (2007) predicts that price reactions should be stronger to good news than to bad news, ceteris paribus. This is because in the good news case, price increases to the extent to reflect the opinions of those who react the most to the signal, whereas in the bad news case, price decreases to the extent to reflect the opinions of those who react the least to the signal. Furthermore, because this asymmetry is driven by short sale constraints and heterogeneous interpretations of the news, it should increase with the heterogeneity in interpretations of news and the costs of short selling. ${ }^{11}$

Note that Xu's (2007) predictions hinge closely on the existence of heterogeneous interpretations of a public signal. In the absence of interpretation heterogeneity, Xu (2007) suggests no asymmetry in the magnitude of the price reactions to good and bad news. In fact, the

\footnotetext{
${ }^{11}$ The prediction, as pointed out by Xu (2007), does not depend on the maintained assumption of investor heterogeneity. For example, investors may disagree about whether an announcement represents changes in long-run growth trends or merely a temporary fluctuation. This dimension of disagreement can be captured by assuming disagreement on the signal's precision. Assuming that investors differ in the precision of their pre-disclosure information but attach the same precision to the public information, as in Kim and Verrecchia (1991), leads to the same prediction. Modeling heterogeneous prior confidence and modeling heterogeneous precision in a new public signal are conceptually equivalent. Assuming as in Kim and Verrecchia (1997) that investors employ different private information, which can be used only in conjunction with a public announcement, will not change the prediction either. This is because such an assumption offers only a particular reason about why investors revise their beliefs differentially. Finally, the prediction holds if we allow investors to have heterogeneous prior expectations about stock value. According to Bayesian updating, disagreement in prior expectations has no implications for value updating. In fact, as long as prior asset valuations and interpretations of the new signals are not perfectly negatively correlated, the prediction in Xu (2007) holds.
} 
existing literature on short sale constraints suggests that when investors exhibit homogeneous interpretations of this signal, a stronger price reaction to bad news than to good news may be observed. This is because short sale constraints, which also exist before the earnings announcements are made, tend to reduce the speed with which prices adjust to private information (Diamond and Verrecchia 1987), especially bad news. Suppose that the information about earnings is taken to be somewhat private until firms announce those earnings to the public. With no heterogeneity in interpretations of these figures, information asymmetry vanishes with the announcement and the market clears, allowing prices to adjust fully to the consensus public information. On average, the announcement would induce a stronger price reaction to bad earnings news. ${ }^{12}$

The above understanding is important in order to explore the full implications of the effect of short sale constraints on the asymmetric price reactions to good and bad news. Given that short sale constraints generally exist and differ only in terms of the degree, in the absence of heterogeneous interpretations, the delayed incorporation of private information (especially negative private information) due to short sale constraints implies that prices react more strongly to bad news than to good news when the news become public. As the degree of heterogeneous interpretations of the news increases, the selective registration of more optimistic opinions imposes an opposite force on the asymmetry, and even leads to an opposite pattern (i.e., prices react more strongly to good news than to bad news). This is because the selective registration of more optimistic opinions implies a convex function of price in the public signal. Furthermore, the patterns described above are expected to be more pronounced when the short sale constraints are more binding. We formalize our hypotheses as follows:

\footnotetext{
${ }^{12} \mathrm{Xu}$ (2007) does not model private information; thus, in his model the impact of short sale constraints on the adjustment speed of prices to pre-disclosure private information does not exist.
} 
HYPOTHESIS: (1) when investors interpret the earnings news homogenously, prices react stronger to bad earnings news than to good earnings news; (2) when investors interpret the news more heterogeneously, prices react more strongly to good earnings news than to bad earnings news; and (3) the patterns stated in (1) and (2) are more pronounced when short sale constraints are more binding.

\section{Research design}

\subsection{Proxies for short sale constraints}

Jones and Lamont (2002) suggest that short sale constraints include the various costs and risks of shorting, as well as legal and institutional restrictions. ${ }^{13}$ Nagel (2005) differentiates between two types of short sale constraints: direct and indirect. The direct cost of borrowing is reflected in the difference between the rebate rate, which the lender pays to the short seller, and the interest rate on cash funds. The indirect costs arise from unfamiliarity with the short selling market, institutional constraints, risk and even cultural pressures. The generally low level of short selling interests in most stocks and the lack of participation in the short selling market by most investors suggest that the indirect constraints on short selling may have an even larger effect than the direct short selling costs. ${ }^{14}$

The existing literature provides several suggestions for how to proxy short sale constraints. We follow the more recent literature and employ institutional ownership to inversely

\footnotetext{
${ }^{13}$ See Jones and Lamont (2002) for a more thorough discussion of the constraints on short selling.

${ }^{14}$ According to Almazan et al. (2004), 70\% of investment managers are precluded from short selling by charter and strategy restrictions. Fewer than $10 \%$ of those eligible to engage in short selling actually do so. Market short interest is typically only about $1.5 \%$ of all shares outstanding.
} 
proxy for short sale constraints (D’Avolio 2002; Nagel 2005; Asquith et al. 2005; Berkman et al. 2009). ${ }^{15}$ Our justification of such a choice is as follows. First, the direct cost of short selling is high in stocks with a low degree of institutional ownership. D'Avolio (2002) shows that institutional investors are the main suppliers of equity loans. Correspondingly, he finds that the degree of institutional ownership can explain much of the variation in loan supplies across stocks, and that stocks with a low level of institutional ownership are more expensive to borrow. Second, most institutional investors never sell short due to institutional constraints or cultural pressures. In the presence of these indirect short sale constraints, sophisticated institutional investors can easily sell an overpriced stock that they own, but will not trade against an overpriced stock that they do not. As a result, short sale constraints are effectively more binding in stocks owned mainly by individual investors; i.e., those with a low degree of institutional ownership (Nagel 2005). ${ }^{16}$

\subsection{Proxies for heterogeneous interpretations}

We employ the abnormal trading volume around earnings announcements to proxy for heterogeneous interpretations. Harris and Raviv (1993), and Kandel and Pearson (1995), among others, suggest that when the differences in investors' interpretations of public news are great,

\footnotetext{
${ }^{15}$ Another proxy for short sale constraints used in previous studies is the level of short interest. We do not use this proxy because Chen et al. (2002) suggest that it is not a good measure of how binding short sale constraints are. They argue that stocks with a low or zero value of short interest may be exactly those that are more costly to sell short. Jones and Lamont (2002) suggest that the short stock rebate rate is a better proxy for measuring the magnitude of short sale constraints. However, the data on rebate rate are proprietary and available for only a very short time period.

${ }^{16} \mathrm{~A}$ number of studies examine the role of institutional ownership in price reactions to earnings announcement. Institutional investors are believed to have superior capability to process public information, better access to company information, and more incentive to acquire private information. Consistent with this view, prior findings show that institutional ownership accelerates the pricing of future earnings (Ayers and Freeman 2003) and the change of institutional ownership on subsequent earnings announcement abnormal returns (Ali et al. 2003). In this paper, we use institutional ownership as a proxy for short sale constraints and derive predictions from the short sale constraints' perspective. We acknowledge that institutional ownership could proxy for investor sophistication. However, this dimension is unlikely to explain the asymmetric price reactions to good news versus bad news conditional on abnormal trading volume.
} 
the trading volume will be higher. Kandel and Pearson (1995) and Bamber et al. (1999) provide empirical evidence that differential interpretations are an important stimulus for trading. Obviously, there are also other reasons for trading. For example, volume may reflect liquidity or portfolio rebalancing. Trading volume around earnings announcements is also positively related to the amount of value-relevant information. As Berkman et al. (2009) point out, these other reasons do not nullify the effects of differences of opinion. These other reasons also do not explain the asymmetric price reactions to good news and bad news. We choose abnormal trading volume (i.e., the average turnover during the earnings announcement event window minus the average turnover in a baseline non-event period) to mitigate the influence of the trading volume that is due to liquidity needs. ${ }^{17}$

\subsection{Data sources and variable definitions}

Our data come from CRSP, COMPUSTAT, I/B/E/S, and the Spectrum database. Our sample consists of all common stocks (i.e., CRSP share code of 10 or 11) listed on the NYSE/AMEX/NASDAQ during the 1985-2007 period that have the data necessary to calculate the earnings surprises (ESURP) and market-adjusted returns (RET) around earnings announcements and a share price above one dollar. Our sample begins in 1985 because there are

\footnotetext{
${ }^{17}$ The KP index, which compares analyst forecasts shortly before and after these announcements (see Kandel and Pearson 1995), is a potential alternative proxy for differential interpretations of earnings news. However, it requires that the same analyst issue forecasts both shortly before and after the earnings announcements. The adoption of this measure would thus significantly affect sample size and statistical power, as most of the small firms (arguably more subject to short sale constraints) would have to be dropped from the sample. As for the change in dispersion of analysts' forecasts, this measure shares the same weakness as the KP index; in addition, it can capture only situations where paired forecasts move in opposite directions and diverge, but not situations where paired forecasts move in opposite directions and flip. Garfinkel (2009) examines the empirical validity of extant proxies for opinion divergence. He finds that measures based on trading volume are highly correlated with his new construct for opinion divergence using proprietary data on investors' orders, while analyst forecast divergence is negatively related to the new construct.
} 
only a small number of analyst quarterly earnings forecasts prior to that year.

We obtain our analyst forecast data from I/B/E/S. We use unadjusted (for splits and stock dividends) I/B/E/S forecasts to avoid the potential rounding problem pointed out by Payne and Thomas (2003). We calculate ESURP as the difference between firm reported quarterly earnings per share (EPS) before extraordinary items and the consensus analyst forecast scaled by the stock price at the end of the fiscal quarter. The stock price deflator renders earnings surprises comparable across stocks and also helps to mitigate heteroscedasticity (Kothari 2001). We calculate the consensus forecast as the median value of individual analyst forecasts. To reduce contamination from stale forecasts, we use only forecasts made within the 60 days prior to the earnings announcement. If one analyst issues more than one forecast within this 60 -day window, then only the most recent is included.

From CRSP, we calculate the three-day, $[-1,+1]$, market-adjusted returns $(R E T)$ around the earnings announcements as a measure of price reactions. The adjustment is based on the CRSP value-weighted market return over the same three-day time window. We calculate abnormal trading volume $(A B V O L)$ as the average turnover during the three days surrounding the earnings announcement minus the average daily turnover in a baseline non-event period. Following prior studies (e.g., Garfinkel and Sokobin 2006), we define the baseline period as the 45 trading day window from trading day -55 to trading day -11 relative to the earnings announcement. Turnover is trading volume divided by shares outstanding. For the NASDAQ stocks, we multiply turnover by 0.5 , because the volumes on the NASDAQ and NYSE/AMEX markets are not comparable due to differences in their dealership structures. ${ }^{18}$ Relative to raw volume, $A B V O L$ captures the abnormal trading that is more likely to be due to differential

${ }^{18}$ Atkins and Dyl (1997) and Anderson and Dyl (2005) find that the NASDAQ volume is overstated by approximately $70 \%$ to $100 \%$ relative to the NYSE volume. We follow Nagel (2005) in using 0.5 . We also try other parameters such as $0.6,0.7$, and 0.8 and obtain similar results. 
interpretations than to other factors such as liquidity (Kandel and Pearson 1995).

We obtain our institutional ownership data from the Spectrum database. Following the literature (e.g., Nagel 2005), we calculate institutional ownership (IO) as the percentage of shares outstanding held by institutional investors, and we use the last reported $I O$ data prior to the quarterly earnings announcements. If there is no institutional ownership data available within the 180 days prior to earnings announcements, then we assume these stocks to have zero institutional ownership. Following previous studies (e.g., Berkman et al. 2009), we set $I O$ to missing if it is greater than or equal to one.

\subsection{Empirical Model}

We estimate the following regression.

$$
R E T_{p t}=\beta_{0}+\beta_{1} G O O D_{p t}+\beta_{2} E S U R P_{p t}+\beta_{3} E S U R P_{p t} \times G O O D_{p t}+\text { Control Variables }+\varepsilon_{p t},
$$

where GOOD is a dummy variable that takes a value of one if ESURP is positive and a value of zero if it is negative. Observations with zero earnings surprises are excluded. Slope coefficient $\beta_{3}$ captures the asymmetric stock price reactions to good versus bad news, controlling for the magnitude of the surprise. To understand the change in asymmetry across groups with different degrees of heterogeneous interpretations and short sale constraints, we run the regression separately for subsamples that are partitioned on the basis of $A B V O L$ and $I O$.

In the main test, we first sort the samples into three groups based on the $I O$ of each stock in each quarter. Within each $I O$ group, we further sort the samples into three groups based on the $A B V O L$ of each stock surrounding earnings announcements. The low, medium, and high groups represent stocks in the bottom 30 percent, middle 40 percent, and top 30 percent of the distribution, respectively. Within each $I O$ and $A B V O L$ group, we then form portfolios of the 
individual stocks by ranking ESURP into 20 portfolios. We estimate regression (1) by defining $R E T$ as the average return and ESURP as the average earnings surprise of all stocks in each earnings surprise portfolio. The dummy variable, GOOD, is coded as one if ESURP is positive, zero if it is negative. Similarly, all of the control variables are defined as the average value in each earnings surprise portfolio. ${ }^{19}$ We analyze the regression at the portfolio rather than firm level for the following reason. Kinney et al. (2002) find that the means and medians of the abnormal stock return distribution for a given level of earnings surprise are reliably positive for positive earnings surprise portfolios and reliably negative for negative earnings surprise portfolios even for earnings surprises very near zero. However, for a given firm, a positive (negative) return conditional on a positive (negative) earnings surprise alone often falls below "probable," where probable is defined as a likelihood of .75 or higher. This finding suggests that earnings surprises measure news with noise, which can be mitigated if analysis is conducted at the portfolio level. This is particularly important because misclassification of news into good news and bad news will hinder the interpretation of results.

Our hypothesis posits that (1) prices react more strongly to bad news than to good news (i.e., $\beta_{3}$ is negative) when there is little or no interpretation heterogeneity (i.e., $A B V O L$ is low); (2) prices react more strongly to good news than to bad news when investors interpret the news more heterogeneously; that is, we expect $\beta_{3}$ to increase or even become positive as we move from low $A B V O L$ to high $A B V O L$; and (3) the patterns in (1) and (2) are more pronounced when short selling is more costly (i.e., when $I O$ is low).

\subsection{Control variables}

\footnotetext{
${ }^{19}$ As mentioned earlier, in the main analysis, we exclude the firm-quarters with zero earnings surprises and rank non-zero ESURP into 20 portfolios. Our results are robust (1) if we include zero ESURP in the ranking and (2) if we form 20 portfolios with 10 portfolios among positive ESURP and 10 among negative ESURP.
} 
A number of accounting studies have identified a set of factors that affect the price reactions to earnings surprises, and we carefully control for these factors. First, we control for earnings persistence. Prior studies suggest that the more persistent an earnings surprise, the greater the impact an earnings innovation has on market participants' expectations of future earnings. As a result, more persistent earnings surprises lead to larger price changes (e.g., Kormendi and Lipe 1987; Easton and Zmijewski 1989). Earlier studies focus on the time-series property of earnings. Freeman and Tse (1992) find that the magnitude of $|E S U R P|$ provides more explanatory power than does the time-series persistence of earnings. More specifically, they find that small earnings surprises are valued as more permanent shifts, whereas large earnings surprises are valued as more transitory shifts, with the marginal price responses declining to near zero as the absolute earnings surprises increase. Following the prior literature (e.g., Subramanyam and Wild 1996; Lipe et al. 1998), we include an interaction term between $|E S U R P|$ and ESURP to control for the S-shaped relationship between price reactions and earnings surprises. ${ }^{20}$ In addition, we control for the lower valuation implications of earnings surprises that consist of special items. Special items are frequently nonrecurring and hence lead to a lower persistence of earnings surprises when firms report them in the quarter (Wild et al. 2001). We separately control for negative and positive special items as they may have different implications on valuation. Specifically, we include an interaction term between ESURP and NEGSPEC (POSSPEC), where NEGSPEC (POSSPEC) equals the absolute value of special items deflated by total assets, if negative (positive), and zero otherwise.

\footnotetext{
${ }^{20}$ Our main analysis focuses on absolute price-scaled earnings surprises (|ESURP $\mid$ ) that are less than 5\%, which eliminates the most extreme transitory surprises at the two tails. However, we still include an interaction term between $|E S U R P|$ and ESURP, as Freeman and Tse (1992) show that the price reactions to earnings surprises are still non-linear in the range of [-5\%, 5\%].
} 
In addition to earnings persistence, growth opportunities are also found to be important for the association between stock returns and earnings surprises. Prior studies (e.g., Collins and Kothari 1989) show that higher growth expectations increase the price responses to earnings. We use the ratio of the market-to-book value of equity $(M / B)$ as of the fiscal-quarter end to proxy for growth opportunities. Earlier studies also suggest that risk (i.e., the systematic component of the volatility of equity cash flows) and the interest rate are important determinants of price reaction or the earnings response coefficient (Easton and Zmijewski 1989; Collins and Kothari 1989). The price reactions to earnings announcements are expected to decrease with risks and interest rates because a higher degree of risk or a high interest rate means a lower discounted present value of the revisions in expectations for future earnings innovations. Following the existing literature, we measure systematic risk (BETA) using a market model estimated over the year ending the day before the start of the relevant fiscal quarter. We measure interest rates by the yield on the CRSP 30-year bond index (BOND30) at the end of the fiscal quarter. Finally, we control for firm size (SIZE), as price reactions may differ across firms of different sizes due to differences in their information environments. We measure it by the market capitalization of the stock at the fiscal quarter-end.

\section{Empirical results}

\subsection{Descriptive Statistics}

Our sample consists of 141,328 quarterly earnings announcements of NYSE/AMEX/NASDAQ stocks between 1985 and 2007 with the data necessary to calculate ESURP and $R E T .^{21}$ Stocks priced below one dollar and observations with zero earnings surprises

\footnotetext{
${ }^{21}$ Following Zhang (2008), we exclude observations with (1) a forecast date on or after the corresponding earnings announcement date, (2) an earnings announcement before or more than 90 days after the corresponding fiscal
} 
or price-deflated absolute earnings surprises greater than 5 percent are excluded. ${ }^{22}$

Table 1 provides preliminary evidence on the asymmetric price reactions to earnings surprises. Earnings surprise decile portfolios are formed for each year-quarter using the full sample in Panel A, within the subsamples sorted in terms of $A B V O L$ in Panel $\mathrm{B}$, and within the subsamples first sorted by $I O$ and then by $A B V O L$ in Panel C. Low, Medium, and High represent stocks in the bottom 30 percent, middle 40 percent, and top 30 percent of the distributions in each year-quarter, respectively. The mean $R E T$ over $[-1,+1]$ around the quarterly earnings announcements in each earnings surprise decile portfolio is also reported.

For the sake of brevity, our discussion here focuses on pattern comparisons of the two extreme decile portfolios. Panel A shows that in the full sample, the average three-day return around earnings announcements is 2.86 percent in the top earnings surprise decile and -1.94 percent in the bottom earnings surprise decile. The difference in the absolute values of the two numbers, as shown in the last column, is 0.92 percent, which suggests that, on average, price reactions are stronger to good news than to bad news.

Panel B further reveals that the pattern of asymmetry in the price reactions to good news versus bad news varies across the volume groups. In the low- $A B V O L$ group, price reactions are actually stronger to bad news than to good news. The average three-day abnormal return in the bottom decile of earnings surprises is -1.39 percent, whereas it is 0.52 percent in the top decile of earnings surprises. As we move to the medium- and high- $A B V O L$ groups, the price reactions become stronger to good news than to bad news. More specifically, the average three-day

quarter end, and (3) an EPS or forecast greater than 10. We also delete observations with earnings announcement dates in COMPUSTAT and I/B/E/S (if available) that differ by more than one calendar day, because such observations are potentially subject to data error or other irregularities.

${ }^{22}$ Around 96\% of price-scaled earnings surprises fall within the [-5\%, 5\%] range. Earnings surprises greater than $5 \%$ are excluded to avoid the undue influence of extreme values, and zero earnings surprises are excluded because our aim is to compare the price reactions to positive and negative news. 
abnormal return in the top decile of earnings surprises is 5.6 percent, compared to -2.92 percent in the bottom decile in the high- $A B V O L$ group. ${ }^{23}$

Finally, Panel C indicates that the pattern across the $A B V O L$ groups in Panel $\mathrm{B}$ can also be observed in each $I O$ subgroup, but it is more pronounced in the low-IO group than in the high-IO group. In sum, the preliminary evidence presented in Table 1 supports our hypothesis that, with little or no interpretation heterogeneity, prices react more strongly to bad earnings news than to good news. However, as investors interpret the news more heterogeneously, prices react more strongly to good news than to bad news, especially when the short sale constraints are more binding.

Table 2 reports the summary statistics for the variables used in the regression analysis. Panel A presents the mean and standard deviation (std) of each variable. The mean of the $R E T$ is positive, 0.4 percent. This finding is consistent with Frazzini and Lamont's (2007) observation that, on average, stock prices rise around earnings announcement dates. On average, 54 percent of the firms in each quarter report good news (GOOD); i.e., they beat the analyst forecasts. It is noteworthy that there is a significant amount of variation in the $A B V O L$ (mean $=0.26$ and std $=$ 0.56), which is consistent with prior findings that earnings announcements are characterized by a significant number of differential interpretations (e.g., Bamber et al. 1999).

Panel B of Table 2 presents the average cross-sectional correlations of the variables. As expected, the three-day market-adjusted returns (RET) are positively correlated with earnings surprises (ESURP) and the good news dummy (GOOD). NEGSPEC is negatively correlated with ESURP, suggesting that large negative earnings surprises tend to be associated with the

\footnotetext{
${ }^{23}$ Panel $\mathrm{B}$ also shows that the absolute values of stock returns around earnings announcements for the two extreme earnings surprise portfolios in the high- $A B V O L$ group are much larger than their counterparts in the low- $A B V O L$ group. To the extent that trading volume and abnormal trading volumes are highly correlated, this result is consistent with previous empirical findings that, on average, absolute price changes and trading volume are positively correlated (Karpoff 1987; Bamber and Cheon 1995).
} 
recognition of a large negative one-time special item. Consistent with prior studies, institutional ownership (IO) is positively correlated with firm size with the correlation coefficient of 0.47 .

\subsection{Main Regression Results}

Tables 3 and 4 report the main regression results. Low, Medium, and High represent stocks in the bottom 30 percent, middle 40 percent, and top 30 percent of the distribution in each year-quarter, respectively. Our sample spans from 1985 to 2007 and consists of 92 quarters.

Table 3 first reports the estimation regression results for the full sample and then those based on the $A B V O L$ subsamples. The first row shows the regression results for the full sample without including the control variables. Consistent with Basu's finding (1997), these results show that the slope coefficient $\left(\beta_{3}\right)$ on the interaction term between GOOD and ESURP is positive and statistically significant. Basu (1997) attributes the stronger price reaction to good news than to bad news to accounting conservatism. He argues that the asymmetrical verification requirements for gains and losses under conservative accounting principle imply the timely recognition of losses and the gradual recognition of gains. As a result, positive earnings surprises may be more persistent and have a larger valuation impact than negative earnings surprises. The second row of Table 3 includes the variables that explicitly control for factors such as earnings

persistence. $\beta_{3}$ is still significantly positive but the magnitude is much smaller, which suggests that the different implications of earnings persistence for positive and negative earnings news that is induced by accounting conservatism is partially captured by the control variables. We next turn to the regression results based on the subsamples conditional on $A B V O L$. If accounting conservatism remains the main driver of the asymmetric reactions as observed in the full sample, then we would expect a consistent significantly positive $\beta_{3}$ across all of the subsamples. 
As previously discussed, theories of heterogeneous interpretations of earnings news in the presence of short sale constraints actually predict a systematic pattern of $\beta_{3}$ across the subsample portfolios sorted by $A B V O L . \beta_{3}$ is expected to be negative in the low- $A B V O L$ sample and to increase in value as we move from the low- to the high-volume groups, and the results in Table 3 are consistent with this prediction. More specifically, the estimated $\beta_{3}$ is -0.53 for the low$A B V O L$ group and increases monotonically to 1.30 for the high- $A B V O L$ group. The difference, 1.82, reported in the bottom row of the table, is highly significant. ${ }^{24}$

The estimation results on the other variables are in line with the prior literature. Consistent with Freeman and Tse (1992), the coefficient on the interaction term between earnings surprises and the absolute value of earnings surprises $\left(\gamma_{1}\right)$ is negative. These results hold for the full sample and all three $A B V O L$-sorted subsamples, and they support the conjecture that the marginal response of stock prices to an earnings surprise declines as the absolute magnitude of that surprise increases. The estimated coefficients on the interaction terms between earnings surprises and NEGSPEC, POSSPEC, the $M / B, B E T A$ and BOND30 are largely in the predicted directions, although not always significant, across the different $A B V O L$ groups. The adjusted- $R^{2}$ varies across the different $A B V O L$ groups, ranging from $27.30 \%$ in the low $A B V O L$ group to $56.26 \%$ in the high $A B V O L$ group. The results suggest that earnings announcements (good news or bad news) on average convey less value-relevant new information in the low $A B V O L$ group than in the high $A B V O L$ group.

Table 4 reports the regression results for the subsamples of double-dependent sorting: first by $I O$ and then by $A B V O L$. Our purpose here is to test the hypothesis that the asymmetry is

\footnotetext{
${ }^{24}$ Following Petersen's (2009) suggestion, we calculate the $t$-statistics using clustered (by time) standard errors to account for the cross-sectional residual dependence within each year-quarter. Throughout the paper, the terms "highly significant," "significant," and "weakly significant" refer to significance at the $1 \%, 5 \%$, and $10 \%$ levels, respectively.
} 
more pronounced for low-IO stocks, which are arguably more bound by short sale constraints and thus tend to have greater short selling costs and risks. Consistent with our prediction, the increase in the estimation of $\beta_{3}$ with abnormal trading volume can be observed for the low- and medium- $I O$ groups, but not for the high-IO group. For the low-IO group, the $\beta_{3}$ coefficients exhibit exactly the same pattern as that shown in the lower panel of Table 3. The coefficients for the low- and high- $A B V O L$ groups are $-0.51(t=-2.86)$ and $1.24(t=3.50)$, respectively, and the difference (1.76) is significant at the $1 \%$ level. A similar but milder pattern also holds for the medium- $I O$ group. The difference between the two $\beta_{3}$ coefficients is 1.21 , which is also significant at the $1 \%$ level. However, $\beta_{3}$ is not significant for any of the volume groups for the high-IO group.

The results in Table 4 reinforce our finding in Table 3 that $A B V O L$, which measures the degree of heterogeneity in interpretations of earnings news, plays an important role in explaining the asymmetric price reactions to good versus bad news. Moreover, these results confirm the importance of the effect of short sale constraints, as we observe no $A B V O L$ effect on price reaction asymmetry in the subsample in which stocks are subject to less binding short sale constraints.

In sum, Tables 3 and 4 provide evidence that when interpretations of earnings news are more heterogeneous, prices react more strongly to good news than to bad, and the effect is more pronounced when the short sale constraints are more binding. This evidence supports the notion that heterogeneous interpretations of earnings announcements have important implications for the price reactions to these announcements in the presence of short sale constraints.

\section{Future analysis}




\subsection{Implications of heterogeneous interpretations on stock returns around earnings}

\section{announcements}

Berkman et al. (2009) argue that, on average, public announcements (including earnings announcements) reduce differences of opinion among investors. They propose that, if overvaluation exists under short sale constraints, ${ }^{25}$ then stocks that are subject to higher differences of opinion and more binding short sale constraints earn significantly lower returns around earnings announcements. Their empirical evidence is consistent with this conjecture, thus lending support to Miller’s (1977) overpricing hypothesis.

The ideas and evidence presented in Berkman et al. (2009) are consistent with the conventional view that when new information is released, differences of opinion among investors tend to be reduced. This view is certainly correct when investors interpret the news homogeneously. However, whether it is correct when investors interpret the news heterogeneously is less clear. In fact, it is well accepted that increased heterogeneity can be induced by a new piece of information. Consequently, in certain cases, we would expect increased rather than decreased divergence following a news event such as an earnings announcement (Kothari 2001).

In this paper, we explicitly examine the implications of the heterogeneous interpretations on stock returns around earnings announcements under the condition of short sale constraints. We argue that another type of overpricing could actually arise around announcements due to the selective registration of opinions in the face of constraints.

To better understand the implications of the findings of this paper and those of Berkman

\footnotetext{
${ }^{25}$ Berkman et al. (2009) attribute the overvaluation to speculative trading before earnings announcements. More specifically, they propose that investors with heterogeneous expectations on the forthcoming earnings engage in speculative trading. In the presence of short sale constraints, optimists are more likely to buy than pessimists are to sell short, leading to overvaluation prior to earnings announcements.
} 
et al. (2009), we perform joint analysis in this section. Following Berkman et al. (2009), we use a volume measure, TURN, as a proxy for differences of opinion prior to earnings announcements. ${ }^{26}$ We continue to use $A B V O L$ to proxy for the heterogeneous interpretations of earnings news; i.e., differences of opinion triggered by the earnings news. TURN is measured by the average turnover from trading day -55 to trading day -11 relative to earnings announcements. $A B V O L$ is the average three-day turnover around earnings announcements minus the average turnover from trading day -55 to trading day -11 relative to these announcements. ${ }^{27}$

Holding TURN constant, we expect more positive average returns for stocks with high $A B V O L$ than for those with low $A B V O L$ because of the selective registration of optimistic opinions hypothesized in this paper. Holding $A B V O L$ constant, we expect more negative average returns for stocks with high TURN than for those with low TURN because the former tend to be more overpriced. If both ideas are independently valid in applicable circumstances, together, we expect that the average abnormal returns around earnings announcements will be lowest for stocks with high TURN and low ABVOL and highest for those with low TURN and high ABVOL.

To be consistent with Berkman et al. (2009), we restrict our sample to the 1985 to 2005 period with earnings announcement dates and stock return information available. We exclude firms in the financial (SIC Codes 6000 to 6999) and regulated industries (SIC Codes 4900 to

\footnotetext{
${ }^{26}$ Berkman et al. (2009) employ five different proxies for differences of opinion prior to earnings announcements. We choose TURN in our replication because it is a volume-based proxy and closely related to our proxy.

${ }^{27}$ Following the prior literature (e.g., Garfinkel and Sokobin 2006), we use the time interval between two earnings announcements as the non-event window to obtain $A B V O L$. This baseline volume happens to be the same window that Berkman et al. (2009) use to form TURN, a proxy for pre-announcement differences of opinion. There may be concerns that the mechanical relationship between TURN and $A B V O L$ is driving the results. As shown in Panel C of this section, however, the average observation in the high- (low-)TURN group is not greatly concentrated in the low(high-) $A B V O L$ group. In fact, only $37.7 \%$ of observations in the high $T U R N$ group fall into the low $A B V O L$ group, and only $14.6 \%$ of observations in the high $A B V O L$ group fall into the low TURN group. The finding presented in Panel $\mathrm{C}$ further rules out the possibility that the results associated with $A B V O L$ are driven by the mechanical relationship between $A B V O L$ and TURN. Nonetheless, we also try an alternative baseline window using one year ending -55 prior to earnings announcements (i.e., the ending date prior to the window for the TURN measure), and our results remain qualitatively the same.
} 
4999). We further exclude the earnings announcements of firms with $\$ 10$ million or less in total assets, $\$ 10$ million or less in the market value of equity, and those whose stock is priced at less than \$1 per share, as reported on COMPUSTAT at the start of the current fiscal quarter. Our final sample consists of 274,529 firm-quarters.

Panel A of Table 5 replicates the main finding in Berkman et al. (2009). We first report the average three-day market-adjusted abnormal returns for portfolios formed on the basis of TURN. ${ }^{28}$ We then examine the joint effect of TURN (opinion difference) and IO (institutional ownership) on earnings announcement period returns using two-dimensional sequential sorts, first sorting the firms into three $I O$ portfolios and then within each $I O$ portfolio sorting them into three TURN portfolios. Low, Medium, and High represent stocks in the bottom 30 percent, middle 40 percent, and top 30 percent of the distribution, respectively. Consistent with Berkman et al. (2009), these result shows that (1) the average abnormal earnings announcement period returns are significantly lower in the high TURN portfolio than in the low TURN portfolio, and (2) this pattern exists only in the low- and medium-IO groups.

Panel B of Table 5 repeats the analysis in Panel A, except that we replace TURN with $A B V O L$, our proxy for heterogeneous interpretations of earnings announcements. In the presence of short sale constraints, the selective registration of more optimistic opinions would suggest an upward pressure on the price, and the greater the heterogeneity in interpretations of the earnings news $(A B V O L)$, the higher the returns around earnings announcements (RET). This is exactly what we find in Panel B. The first row of this panel suggests that firms with high $A B V O L$ earn

\footnotetext{
${ }^{28}$ To be consistent, we strictly follow Berkman et al. (2009). We first compute the average three-day abnormal return for every portfolio in each of the 84 calendar quarters. The reported portfolio returns are precision-weighted averages of this sequence of quarterly averages, where the number of observations in each quarter is used to proxy for the precision of the quarterly average.
} 
significantly higher average returns than do firms with low $A B V O L \cdot{ }^{29}$ Further evidence from the two-dimensional sequential sorts on $A B V O L$ and $I O$ suggests that this pattern is more pronounced when stocks are more difficult to sell short (when $I O$ is low). ${ }^{30}$

Panel C explores the joint implications of TURN and ABVOL. We independently sort the stocks into three TURN portfolios and three $A B V O L$ portfolios. The average observations per quarter and the average three-day market-adjusted market returns in each of the 3-by-3 portfolios are reported. This presentation format allows several insights into the individual and joint effects of TURN and $A B V O L$. First, the average abnormal returns always increase when we move down the table from high TURN to low TURN and to the right from low ABVOL to high $A B V O L$, thus corroborating our findings in Panels A and B. Second, when $A B V O L$ is low (i.e., when interpretations of earnings announcements are more homogeneous), the average abnormal returns are negative in all three TURN groups and the most negative in the high TURN group. These results are consistent with the conjecture made by Berkman et al. (2009) that earnings announcements correct overvaluation, especially that of stocks with highly dispersed opinions prior to the announcements. However, when $A B V O L$ is high, we observe the opposite: abnormal returns are, on average, positive, which is consistent with our expectation that, due to the selective registration of optimistic opinions, the greater the heterogeneity in interpretations of earnings news, the higher the returns around earnings announcements. Finally, we observe that

\footnotetext{
${ }^{29}$ Rees and Thomas (2010) find a negative relationship between the stock returns around earnings announcement and the change of trading volume. They focus on the change of trading volume before (trading day -20 to trading day -2 ) and after (trading day +2 to trading day +20 ). We focus on the trading volume around the earnings announcement (trading day -1 to trading day +1 ) as trading volume around the announcement better captures heterogeneous interpretations triggered by the public announcement.

${ }^{30}$ Hong and Stein (2007) suggest that news announcements may simultaneously spark increased disagreement among those investors who were already following the stock and grab the attention of those who were not. They further argue that in either case, the same end result is expected: both more trading volume and -in the presence of a short sale constraint—concurrent upwards pressure on the price. The attention-grabbing story has drawn attention in the recent literature (e.g., Frazzini and Lamont 2007). We believe that both attention grabbing and increased disagreement contribute the observed phenomenon. Disentangling these two effects is beyond the scope of our study.
} 
the cell with the highest TURN and lowest $A B V O L$ has the lowest average abnormal returns (0.76\%), whereas that with the lowest $T U R N$ and highest $A B V O L$ has the highest (3.80\%). Our findings suggest that these two volume measures capture different effects, with the former being driven by pre-earnings announcement speculation and the latter by differential interpretations of the earnings announcements. We feel that the findings of this joint analysis are both interesting and important, as they shed light on the interplay between the price and volume effects of earnings announcements from a different angle. The return pattern suggests that, on one hand, earnings announcements constitute a corrective force for the possible overvaluation induced by speculative purchasing prior to these announcements being made. On the other hand, they can trigger disagreement, and selective registration due to short sale constraints gives rise to overpricing.

\subsection{Implications of heterogeneous interpretation on PEAD}

In this section, we explore the implications of the short-run asymmetric price effects due to short sale constraints and heterogeneous interpretations of earnings announcements on the long-standing PEAD anomaly. Lerman et al. (2008) assert that, despite decades of research, we are still unsure why the PEAD exists, but we know empirically that it is generally larger for smaller, lower-priced, less-liquid firms with less institutional following (e.g., Latane and Jones

1979; Bernard and Thomas 1989; Bhushan 1994; Bartov et al. 2000). Although the two strains of theoretical literature cited in this paper (i.e., heterogeneous interpretations of public information and short sale constraints) offer predictions about the peculiar asymmetric patterns of the immediate price reactions to earnings announcements, they remain silent about the possible shapes taken by PEAD for portfolios sorted by either $A B V O L$ or $I O$ or both. 
The existing empirical literature offers a number of clues about PEAD patterns. For example, Garfinkel and Sokobin (2006) argue that PEAD can be tied in part to the divergence in investors' opinions, as they find a positive correlation between the abnormal trading volume in the three-day period around earnings announcements and abnormal returns over the subsequent 60 trading days. Reed (2007) argues that the costs of short selling reduce the information efficiency (Diamond and Verrecchia 1987) of private information before these announcements, and the same logic can be extended to the earnings announcement setting if the price reactions to the earnings news are incomplete or if information asymmetry does not vanish upon the earnings news being publicized. In particular, the full incorporation of negative earnings surprises would be further delayed. To the extent that PEAD is related to the delayed incorporation of information into prices, as suggested by the mounting evidence in the PEAD literature, the asymmetry patterns in three-day returns may carry over to the longer time window over which PEAD occurs. The purpose of this section is thus to join the aforementioned empirical literature by documenting the additional stylized PEAD patterns for stocks with various degrees of short sale constraints and heterogeneous earnings interpretations.

Table 6 provides our empirical analysis of these returns over the drift window following good news and bad news. To be consistent with our main analysis, we use the same sample; i.e., that consisting of 141,328 quarterly earnings announcements of NYSE/AMEX/NASDAQ firms from 1985 to $2007 .{ }^{31}$ Following the tradition of the PEAD literature (e.g., Bernard and Thomas 1989; Bartov et al. 2000; Zhang 2008), we use 60-day size-adjusted returns starting from two days after the earnings announcements and ending 61 days after the earnings announcements.

\footnotetext{
${ }^{31}$ To maintain consistency with our three-day return analysis, our sample excludes zero earnings surprises and pricedeflated absolute earnings surprises greater than $5 \%$. We repeat our analysis including all earnings surprises, and the results are qualitatively the same.
} 
More specifically, RET60 is abnormal returns adjusted for returns of NYSE/AMEX/NASDAQ firms of the same size decile. For brevity, we report only the average size-adjusted abnormal returns for the portfolio with ESURP ranked in the highest and lowest deciles, as well as the hedge returns with a long position in the high-ESURP group and a short position in the lowESURP. We also report the percentage of the hedge returns that comes from the long position. This measure offers insights into the magnitude of abnormal returns following good news (D10) relative to that following bad news (D1); i.e., it is a measure of asymmetry. As previously mentioned, we employ institutional ownership (IO) to inversely proxy for short sale constraints and the abnormal trading volume around earnings announcements ( $A B V O L)$ to proxy for heterogeneous interpretations of earnings news. ${ }^{32}$ Low, Medium, and High represent stocks in the bottom 30 percent, middle 40 percent, and top 30 percent of the distribution, respectively.

Panel A of Table 6 reports PEAD conditional on ABVOL. Consistent with the prior literature, we find that post-earnings-announcement returns are positively related to $A B V O L$ (Garfinkel and Sokobin 2006; Lerman et al. 2008) ${ }^{33}$ and that hedging portfolio returns with long (short) positions in the top (bottom) decile of earnings surprises also increase with $A B V O L$ (Lerman et al. 2008). Hedging returns monotonically increase from 2.65\% (low $A B V O L$ ) to 4.53\% and then to 5.91\% (high $A B V O L$ ). However, the sources of the hedging portfolio returns differ between the low- and high- $A B V O L$ groups. In the low $A B V O L$ group, the absolute value of

\footnotetext{
${ }^{32}$ We continue to use the abnormal trading volume in the three-day announcement window to proxy for opinion divergence over the drift period. We argue that the disagreement around this three-day window reflects the nature of the earnings news. If the news is more difficult to interpret over the three-day window, then we expect the divergence of opinion about it continue to be greater over the drift window relative to news that is easy to interpret.

${ }^{33}$ Garfinkel and Sokobin (2006) interpret investor opinion divergence as a relevant risk factor and attribute the positive relationship between abnormal trading volume and subsequent returns to fair compensation for risk. Anderson et al. (2007) support the notion that opinion divergence is a risk factor that is priced. However, Lerman et al. (2008) argue that several pieces of evidence seem inconsistent with this risk explanation and suggest the greater demand associated with stock visibility as an alternative explanation. In this study, we do not intend to offer an explanation for the association between abnormal volume and return per se; instead, we explore the asymmetry of subsequent stock returns following good news versus bad news, conditional on abnormal volume and short sale constraints.
} 
the abnormal returns following bad news is larger than that following good news. This asymmetry is reversed in the high- $A B V O L$ group. More specifically, in the low- $A B V O L$ group, the abnormal return to the short position in the lowest ESURP decile is $-2.57 \%$, whereas that to the long position in the highest ESURP decile is $0.08 \%$. In the high- $A B V O L$ group, the abnormal return in the bottom decile of ESURP is $-0.93 \%$, whereas that in the top decile of ESURP is 4.98\%. The return pattern resembles the conditional (on $A B V O L$ ) asymmetry of good news versus bad news in the three-day reaction window. This seems to suggest that prices continue to react to earnings announcements and that the asymmetry in the three-day window is carried over.

Panel B of Table 6 attempts to show the extent to which the degree of short sale constraints affects the asymmetry of abnormal returns following good versus bad news in the drift window. There are a few interesting observations. First, all three sets of $I O$-sorted portfolios preserve the major patterns across the $A B V O L$-sorted portfolios in Panel A. Second, further sorting the stocks based on $I O$, in general, amplifies the $A B V O L$ effect on PEAD. Conditional on comparable levels of $A B V O L$, the lower the $I O$, the higher the hedging portfolio returns. These results hold in all three sets of $A B V O L$ portfolios. Thus, to take advantage of the PEAD anomaly, a zero-investment long-short portfolio focused on stocks with low IO and high ABVOL would generate the highest abnormal returns. If PEAD is a result of gradually impounding information into stock prices for whatever reason, then the foregoing results suggest that short sale constraints and the heterogeneous interpretations of announced earnings may both play a role in the impediment. Third, we note that the proportion of hedge returns from the long position in good news stocks is generally lower when $I O$ is low. One possible explanation is that during the longer time window of 60 days, the negative opinions previously withheld by short sale 
constraints gradually find their way into the price, thus increasing the magnitude of the drift following bad news. ${ }^{34}$

Bernard and Thomas (1989, p. 28) observe that the abnormal returns to the short position over 60 and 180 post-announcement days are $1.9 \%$ and $4.4 \%$, respectively, compared to $2.8 \%$ and $5.4 \%$ to the long position. ${ }^{35}$ A similar asymmetric pattern (i.e., greater abnormal returns for the long position than for the short position) can also be found using different time periods and different earnings surprise measures (e.g., Collins and Hribar 2000; Doyle et al. 2006; Lerman et al. 2008; Ng et al. 2008). Bernard and Thomas (1989) point out that the transaction cost story cannot fully explain this pattern, because to compensate for restrictions on short sales, one would expect returns to the short position to exceed those to the long position. Under the delayed response framework, prices continue to react to earnings news beyond the announcement window. With this view in mind, we argue that the selective registration of more optimistic opinions over the drift window potentially offer an explanation for the asymmetry. The relationship between the abnormal trading volume and the asymmetry of the drift following good news versus the drift following bad news is consistent with this conjecture.

\section{Conclusion}

Heterogeneous interpretations have received growing attention in both the accounting and finance literature. It is now well recognized that even when individuals observe common information, they may still disagree about its implications. A number of accounting studies have

\footnotetext{
${ }^{34}$ Consistent with other recent work, we use a low degree of institutional ownership to proxy for more binding short sale constraints. In the PEAD literature, a low degree of institutional ownership is also used to proxy for less sophisticated investors. The patterns revealed in Panel B suggest that institutional ownership seems to capture both.

${ }^{35}$ Bernard and Thomas (1989) observe that the abnormal returns for short positions are larger than those for long positions when abnormal returns involve summing daily returns. However, they point out that summing returns can introduce noise, and hence they draw inferences based on compounding the returns.
} 
examined how heterogeneous interpretations affect the volume reactions to public announcements (e.g., Kandel and Pearson 1995; Bamber and Cheon 1995; Bamber et al. 1999). In the setting of the price reactions to earnings announcements, prior studies generally assume that these price reactions reflect average opinions; hence, they are unaffected by differences of opinion. We provide compelling evidence to show that the heterogeneous interpretations of earnings announcements have important implications for the price reactions to these announcements in the presence of short sale constraints. More specifically, we provide evidence to show that with little or no interpretation heterogeneity, the price reactions are stronger to bad news. However, when interpretations become more heterogeneous, price reactions become stronger to good news. This pattern is more pronounced when short sale constraints are more binding. As heterogeneous interpretations are considered as one important source of abnormal trading volume, our evidence on the significant interplay between the price and volume reactions to earnings announcements also adds to the resurgence of interest in connecting trading activity to prices through the disagreement model (Hong and Stein 2007).

A recent related study carried out by Berkman et al. (2009) also investigates the price reactions to earnings announcements under short sale constraints and different opinions. They hypothesize that, under short sale constraints, speculative trading prior to earnings announcements leads to overpricing, which is then corrected by the announcements. The intuition is that earnings announcements reduce prior opinion divergence and consequently reduce overvaluation. We perform joint analysis of the price reaction effects by taking into account both pre-announcement opinion divergence and opinion divergence triggered by heterogeneous interpretations of the earnings news. We find that when firms are double-sorted by both types of divergence, stocks with a large degree of pre-announcement opinion divergence, 
but homogeneous interpretations of earnings news, earn the lowest abnormal returns around earnings announcements, whereas those with a small degree of pre-announcement opinion divergence, but more heterogeneous interpretations of earnings news, earn the highest abnormal returns around earnings announcements. We conclude that the effect identified in this paper plays an equally important role to that identified in Berkman et al. (2009) in understanding the implications of short sale constraints on stock returns around earnings announcements. The evidence presented here confirms the double-role notion of earnings announcements. Namely, whereas earnings announcements typically narrow the heterogeneity of prior beliefs to a certain degree by resolving the uncertainty about the earnings news, increased heterogeneity is also possible if market participants differ in the way in which they interpret the earnings announcements (Kothari 2001). 


\section{REFERENCES}

Almazan, A. K., Brown, C., Carlson, M. D., Chapman, D. A., 2002. Why constrain your mutual fund manager? Working paper, University of Texas at Austin.

Ali, A., Hwang, L.S., Trombley, M.A., 2003. Arbitrage risk and the book-to-market anomaly. Journal of Financial Economics 69, 355 - 373.

Anderson, A-M., Dyl, E.A., 2005. Market structure and trading volume. The Journal of Financial Research 28 (1), 115-131.

Anderson, K. L., Harris, J.H., So, E.C., 2007. Opinion divergence and post-earnings announcement drift. Working Paper.

Asquith, P., Pathak, P.A., Rittera, J.R., 2005. Short interest, institutional ownership, and stock returns. Journal of Financial Economics 78 (2), 243-276.

Atkins, A. B., Dyl, E.A., 1997. Market structure and reported trading volume: NASDAQ versus the NYSE. The Journal of Financial Research 20 (3), 291-304.

Ayers, B.C., Freeman, R.N., 2003. Evidence that analyst following and institutional ownership accelerate the pricing of future earnings, Review of Accounting Studies 8, 1-47.

Bachelier, L. Theory of speculation (translation of the 1900 French edition). In The Random Character of Stock Prices, P. H. Cootner, ed. Cambridge, MA: MIT Press (1964), 17-78.

Bamber, L. S., Barron, O.E., Stober, T.L., 1999. Differential interpretations and trading volume. Journal of Financial and Quantitative Analysis 34 (3), 369-385.

Bamber, L. S., Cheon, Y.S., 1995. Differential price and volume reactions to accounting earnings announcements. The Accounting Review 70 (3), 417-441.

Barron, O., Byard, D., Kim, O., 2002. Changes in analysts' information around eanrings announcements. The Accounting Review 77, 821-846. 
Bartov, E., Radhakrishnan, S., Krinsky, I., 2000. Investor sophistication and patterns in stock returns after earnings announcements. The Accounting Review 75 (1), 43-63.

Basu, S., 1997. The conservatism principle and the asymmetric timeliness of earnings. Journal of Accounting and Economics 24 (1), 3-37.

Beaver, W. H. 1968. The information content of annual earnings announcements. Journal of Accounting Research 6 (3), 67-92.

Berkman, H., Dimitrov, V., Jain, P.C., Koch, P.D., Tice, S. 2009. Sell on the news: Differences of opinion, short-sales constraints, and returns around earnings announcements. Journal of Financial Economics 92 (3), 376-399.

Bernard, V. L., Thomas, J.K, 1989. Post-earnings-announcement drift: Delayed price response or risk premium? Journal of Accounting Research 27, 1-36.

Bhushan, R. 1994. An informational efficiency perspective on the post-earnings announcement drift. Journal of Accounting and Economics, 18, 45-65.

Boehme, R. D., Danielsen, B.R., Sorescu, S.M., 2006. Short-sale constraints, differences of opinion, and overvaluation. Journal of Financial and Quantitative Analysis 41 (2), 455487.

Chang, E. C., Cheng, J.W., Yu, Y., 2007. Short-sales constraints and price discovery: Evidence from the Hong Kong market. The Journal of Finance 62 (5), 2097-2121.

Chen, J., Hong, H., Stein, J.C., 2002. Breadth of ownership and stock returns. Journal of Financial Economics 66 (2, 3), 171-205.

Collins, D. W., Hribar, P., 2000. Earnings-based and accrual-based market anomalies: One effect or two? Journal of Accounting and Economics 29 (1), 101-123. 
Collins, D. W., Kothari, S.P., 1989. An analysis of intertemporal and cross-sectional determinants of earnings response coefficients. Journal of Accounting and Economics 11 (2, 3), 143-181.

Courtenay, S.M., Crum, R.P., Keller, S.B., 1989. Differential reactions to legislative signaling during the enactment of ERTA and TEFRA: An empirical investigation of market returns and volume. Journal of Accounting and Public Policy 8 (4), 283-321

D'Avolio, G. 2002. The market for borrowing stock. Journal of Financial Economics 66 (2, 3), 271-306.

Diamond, D. W., Verrecchia, R.E., 1987. Constraints on short-selling and asset price adjustment to private information. Journal of Financial Economics 18 (2), 277-311.

Diether, K. B., Malloy, C.J., Scherbina, A., 2002, Differences of opinion and the cross-section of stock returns. Journal of Finance 57, 2113-2141.

Doyle, J. T., Lundholm, R.J., Soliman, M., 2006. The extreme future stock returns following I/B/E/S earnings surprises. Journal of Accounting Research 44 (5), 849-887.

Easton, P. D., Zmijewski, M.E., 1989. Cross-sectional variation in the stock market response to accounting earnings announcements. Journal of Accounting and Economics 11 (2, 3), $117-141$.

Figlewski, S. 1981. The informational effects of restrictions on short sales: Some empirical evidence. Journal of Financial and Quantitative Analysis 16 (4), 463-476.

Francis, J., Lafond, R., Olsson, P., Schipper, K., 2007. Information uncertainty and postearnings-announcement-drift. Journal of Business Finance \& Accounting 34 (3, 4), 403433. 
Frazzini, A., Lamont, O.A., 2007. The earnings announcement premium and trading volume. NBER Working paper No. W13090.

Freeman, R. N., Tse, S.Y., 1992. A nonlinear model of security price responses to unexpected earnings. Journal of Accounting Research 30 (2), 185-209.

Garfinkel, J. A., Sokobin, J., 2006. Volume, opinion divergence, and returns: A study of postearnings announcement drift. Journal of Accounting Research 44 (1), 85-112.

Garfinkel, J.A., 2009. Measuring investors' opinion divergence. Journal of Accounting Research, 47 (5), 1317-1348.

Hand, J. R. M., 2002. Discussion of "Earnings surprises, growth expectations, and stock returns, or, don’t let an earnings torpedo sink your portfolio.” Review of Accounting Studies, 7, 313-318.

Harris, M., Raviv, A., 1993. Differences of opinion make a horse race. The Review of Financial Studies (1986-1998) 6 (3), 473-506.

Hong, H., Scheinkman, J., Xiong, W., 2006. Asset float and speculative bubbles. CFA Digest 36 (4), 55-56.

Hong, H., Stein, J.C., 2007. Disagreement and the stock market. The Journal of Economic Perspectives 21 (2), 109-128.

Hope, Ole-Kristian., Thomas, W.B., Winterbotham, G., 2009. Geographic earnings disclosure and trading volume, Journal of Accounting and Public Policy 28 (3), 167-188.

Jarrow, R. 1980. Heterogeneous expectations, restrictions on short sales, and equilibrium asset prices. The Journal of Finance 35 (5), 1105-1113.

Jones, C. M., Lamont, O.A., 2002. Short-sale constraints and stock returns. Journal of Financial Economics 66 (2, 3), 207-239. 
Kandel, E., Pearson, N.D., 1995. Differential interpretation of public signals and trade in speculative markets. The Journal of Political Economy 103 (4), 831-872.

Karpoff, J. 1987. The relation between price changes and trading volume: A survey. Journal of Financial and Quantitative Analysis 22, 109-126.

Kim, O., Verrecchia, R.E., 1991. Trading volume and price reactions to public announcements. Journal of Accounting Research 29 (2), 302-321.

- 1997. Pre-announcement and event-period private information. Journal of Accounting and Economics 24 (3), 395-420.

Kinney, W., Burgstahler, D., Martin, R., 2002. Earnings surprise “materiality” as measured by stock returns. Journal of Accounting Research 40 (5), 1297-1329.

Kormendi, R., Lipe, R., 1987. Earnings innovations, earnings persistence, and stock returns. The Journal of Business 60 (3), 323-345.

Kothari, S. P. 2001. Capital markets research in accounting. Journal of Accounting and Economics 31 (1-3), 105-231.

Latane, H. A., Jones, C.P., 1979. Standardized unexpected earnings-1971-77. Journal of Finance 34, 717-724.

Lerman, A., Livnat, J., Mendenhall, R.R., 2008. The high-volume return premium and postearnings announcement drift. Working paper, New York University and University of Notre Dame.

Lintner, J. 1969. The aggregation of investors' diverse judgments and preferences in purely competitive security markets. Journal of Financial \& Quantitative Analysis 4 (4), 347400. 
Lipe, R. C., Bryant, L, Widener, S.K., 1998. Do nonlinearity, firm-specific coefficients, and losses represent distinct factors in the relation between stock returns and accounting earnings? Journal of Accounting and Economics 25 (2), 195-214.

Lu, H. 2004. Information diffusion and the boundary of market efficiency: Empirical evidence from earnings announcements. Working paper, University of Southern California.

Mashruwala, C. A., Mashruwala, S.D. Bharat, S., 2009. Short-sales constraints, investor disagreement, and the asymmetric market reaction to earnings news. Working paper.

Miller, E. M. 1977. Risk, uncertainty, and divergence of opinion. The Journal of Finance 32 (4), 1151-1168.

Morris, S. 1996. Speculative investor behavior and learning. The Quarterly Journal of Economics 111 (4), 1111-1133.

Nagel, S. 2005. Short sales, institutional investors and the cross-section of stock returns. Journal of Financial Economics 78 (2), 277-309.

Ng, J., Rusticus, T.O., Verdi, R.S., 2008. Implications of transaction costs for the post-earnings announcement drift. Journal of Accounting Research 46 (3), 661-696.

Payne, J. L., Thomas, W.B., 2003. The implications of using stock-split adjusted I/B/E/S data in empirical research. The Accounting Review 78 (4), 1049-1067.

Petersen, M. A. 2009. Estimating standard errors in finance panel data sets: Comparing approaches. The Review of Financial Studies 22 (1), 435-480.

Reed, A. V. 2007. Costly short-selling and stock price adjustment to earnings announcements. Working paper, The University of North Carolina at Chapel Hill.

Rees, L., Thomas, W., 2010. The stock price effects of changes in dispersion of investor beliefs during earnings announcements. Review of Accounting Studies, 19, 1-31. 
Scheinkman, J. A., Xiong, W., 2003. Overconfidence and speculative bubbles. The Journal of Political Economy 111 (6), 1183-1219.

Skinner, D. J., Sloan, R.G., 2002. Earnings surprises, growth expectations, and stock returns or don’t let an earnings torpedo sink your portfolio. Review of Accounting Studies, 7, 289-312.

Subramanyam, K. R., Wild, J.J., 1996. Going-concern status, earnings persistence, and informativeness of earnings. Contemporary Accounting Research 13 (1), 251-273.

Varian, H. R., 1989. Differences of opinion in financial markets. In Financial Risk: Theory, Evidence and Implications. Edited by Courtenay C. Stone, Boston, MA: Kluwer Academic Publishers.

Wild, J. J., Bernstein, L.A., Subramanyam, K.R., 2001. Financial Statement Analysis. Seventh ed: McGraw-Hill/Irwin.

Xu, J. 2007. Price convexity and skewness. The Journal of Finance 62 (5), 2521-2552.

Zhang, Y. 2008. Analyst responsiveness and the post-earnings-announcement drift. Journal of Accounting and Economics 46 (1), 201-215.

Zhang, X. F. 2006. Information uncertainty and stock returns. The Journal of Finance 61 (1), $105-137$. 


\section{Table 1 Asymmetric Price Reactions to Earnings Surprises: Using a Three-Day Reaction Window}

This table reports the mean abnormal returns (RET) for decile portfolios based on the price-scaled earnings surprises (ESURP). RET is the three-day, [-1, 1], return around the quarterly earnings announcements adjusted by the CRSP value-weighted market return. ESURP is the difference between firm reported quarterly earnings per share (EPS) before extraordinary items and the consensus analyst forecast scaled by the stock price at the fiscal quarterend. Consensus analyst forecast is the median analyst forecasts made within 60 days prior to the earnings announcement date. Panel A forms the earnings surprise portfolios in the full sample. Panel B forms the earnings surprise portfolios within the subsamples sorted in terms of abnormal trading volume $(A B V O L)$ by each year-quarter. Panel $C$ forms the earnings surprise portfolios within the subsamples first sorted by institutional ownership (IO) and then by abnormal trading volume $(A B V O L)$ by each year-quarter. Abnormal trading volume $(A B V O L)$ is the average turnover over $[-1,+1]$ minus the average turnover over [-55, -11] relative to the earnings announcements. Turnover is trading volume divided by the shares outstanding, multiplied by 0.5 for NASDAQ stocks. $I O$ is the last reported percentage of shares outstanding held by institutional investors within the 180 days prior to the earnings announcements. Low, Medium, and High represent stocks in the bottom 30\%, middle 40\%, and top 30\% of the distribution, respectively. Stocks priced below one dollar are excluded. Zero earnings surprises and price-deflated absolute earnings surprises greater than $5 \%$ are also excluded. The final sample consists of 141,328 quarterly earnings announcements of NYSE/AMEX/NASDAQ firms from 1985 to 2007 with the data necessary to calculate ESURP and RET.

\begin{tabular}{|c|c|c|c|c|c|c|c|c|c|c|c|}
\hline \multicolumn{12}{|c|}{ Panel A: Full Sample } \\
\hline & D1 & D2 & D3 & D4 & D5 & D6 & D7 & D8 & D9 & D10 & $|\mathrm{D} 10|-|\mathrm{D} 1|$ \\
\hline Full Sample & $-1.94 \%$ & $-1.46 \%$ & $-1.26 \%$ & $-0.88 \%$ & $-0.26 \%$ & $0.74 \%$ & $1.46 \%$ & $1.80 \%$ & $2.48 \%$ & $2.86 \%$ & $0.92 \%$ \\
\hline \multicolumn{12}{|c|}{ Panel B: Sort on Abnormal Trading Volume $(A B V O L)$} \\
\hline & D1 & D2 & D3 & D4 & D5 & D6 & D7 & D8 & D9 & D10 & $|\mathrm{D} 10|-|\mathrm{D} 1|$ \\
\hline Low $A B V O L$ & $-1.39 \%$ & $-1.13 \%$ & $-0.87 \%$ & $-0.68 \%$ & $-0.22 \%$ & $0.17 \%$ & $0.26 \%$ & $0.34 \%$ & $0.62 \%$ & $0.52 \%$ & $-0.87 \%$ \\
\hline Medium $A B V O L$ & $-1.44 \%$ & $-0.87 \%$ & $-0.63 \%$ & $-0.21 \%$ & $0.23 \%$ & $0.89 \%$ & $1.35 \%$ & $1.59 \%$ & $1.75 \%$ & $2.26 \%$ & $0.82 \%$ \\
\hline High $A B V O L$ & $-2.92 \%$ & $-2.87 \%$ & $-2.38 \%$ & $-2.15 \%$ & $-0.63 \%$ & $1.43 \%$ & $2.89 \%$ & $3.72 \%$ & $4.93 \%$ & $5.60 \%$ & $2.68 \%$ \\
\hline
\end{tabular}




\begin{tabular}{|c|c|c|c|c|c|c|c|c|c|c|c|c|}
\hline \multicolumn{13}{|c|}{ Panel C: Sort on Institutional Ownership $(I O)$ and Abnormal Trading Volume $(A B V O L)$} \\
\hline \multirow{4}{*}{ High $I O$} & & D1 & $\mathrm{D} 2$ & D3 & D4 & D5 & D6 & D7 & D8 & D9 & D10 & |D10|-|D1| \\
\hline & Low $A B V O L$ & $-0.55 \%$ & $-0.52 \%$ & $-0.46 \%$ & $-0.35 \%$ & $0.07 \%$ & $0.32 \%$ & $0.50 \%$ & $0.69 \%$ & $0.85 \%$ & $0.81 \%$ & $0.26 \%$ \\
\hline & Medium $A B V O L$ & $-0.43 \%$ & $-0.20 \%$ & $-0.06 \%$ & $-0.27 \%$ & $0.48 \%$ & $1.11 \%$ & $1.82 \%$ & $1.83 \%$ & $2.25 \%$ & $1.98 \%$ & $1.54 \%$ \\
\hline & High $A B V O L$ & $-2.92 \%$ & $-3.11 \%$ & $-2.89 \%$ & $-2.39 \%$ & $-0.56 \%$ & $0.67 \%$ & $2.99 \%$ & $3.40 \%$ & $4.05 \%$ & $5.08 \%$ & $2.16 \%$ \\
\hline \multirow{3}{*}{ Median $I O$} & Low $A B V O L$ & $-1.37 \%$ & $-1.16 \%$ & $-0.89 \%$ & $-0.57 \%$ & $-0.10 \%$ & $0.07 \%$ & $0.35 \%$ & $0.42 \%$ & $0.50 \%$ & $1.00 \%$ & $-0.36 \%$ \\
\hline & Medium $A B V O L$ & $-1.12 \%$ & $-0.72 \%$ & $-0.62 \%$ & $-0.14 \%$ & $0.31 \%$ & $0.81 \%$ & $1.40 \%$ & $1.54 \%$ & $1.68 \%$ & $2.24 \%$ & $1.12 \%$ \\
\hline & High $A B V O L$ & $-2.88 \%$ & $-2.86 \%$ & $-2.81 \%$ & $-2.24 \%$ & $-0.47 \%$ & $1.31 \%$ & $2.48 \%$ & $3.97 \%$ & $5.29 \%$ & $5.29 \%$ & $2.42 \%$ \\
\hline \multirow{3}{*}{ Low IO } & Low $A B V O L$ & $-1.85 \%$ & $-1.39 \%$ & $-1.17 \%$ & $-1.06 \%$ & $-0.74 \%$ & $-0.22 \%$ & $-0.08 \%$ & $-0.03 \%$ & $0.23 \%$ & $0.11 \%$ & $-1.74 \%$ \\
\hline & Medium $A B V O L$ & $-1.87 \%$ & $-1.51 \%$ & $-0.86 \%$ & $-0.63 \%$ & $-0.01 \%$ & $0.74 \%$ & $1.10 \%$ & $0.96 \%$ & $1.55 \%$ & $1.74 \%$ & $-0.13 \%$ \\
\hline & High $A B V O L$ & $-3.45 \%$ & $-3.00 \%$ & $-2.33 \%$ & $-1.45 \%$ & $-0.49 \%$ & $2.08 \%$ & $3.20 \%$ & $4.17 \%$ & $4.88 \%$ & $6.29 \%$ & $2.84 \%$ \\
\hline
\end{tabular}


Table 2

\section{Descriptive Statistics for Variables in the Main Regression Analysis}

$R E T$ is the three-day, $[-1,1]$, return around the quarterly earnings announcements, adjusted by the CRSP value-weighted market return. ESURP is the difference between firm reported quarterly earnings per share (EPS) before extraordinary items and the consensus analyst forecast scaled by the stock price at the fiscal quarter-end. Consensus analyst forecast is the median value of individual analyst forecasts made within the 60 days prior to the earnings release date. If an analyst issued more than one forecast within this 60-day window, then only the most recent is used. GOOD is a dummy variable coded as one if ESURP is positive and zero if negative. NEGSPEC (in \%) is the absolute value of special items deflated by total assets if negative, and zero otherwise. POSSPEC (in \%) is the value of special items deflated by total assets if positive, and zero otherwise. $M / B$ is the market-to-book ratio at the fiscal quarter-end. BETA is the systematic risk measured through a market model estimated over the year ending the day before the start of the relevant fiscal quarter. BOND30 (in \%) is the yield on the CRSP 30-year bond index at the end of the fiscal quarter. SIZE is the market capitalization of the stock at the fiscal quarter-end. We take the logarithm of SIZE to adjust for its asymmetric distribution. To mitigate the influence of extreme values, we truncate $M / B$ and BETA at the $1 \%$ and $99 \%$ level. We truncate NEGSPEC and POSSPEC at the $99 \%$ level. $A B V O L$ is the average turnover over [-1, +1$]$ minus the average turnover over $[-55,-11]$ relative to the earnings announcements. Turnover is trading volume divided by shares outstanding, multiplied by 0.5 for NASDAQ stocks. $I O$ (in \%) is the last reported percentage of shares outstanding held by institutional investors within the 180 days prior to the earnings announcements. Stocks priced below one dollar are excluded. Zero earnings surprises and price-deflated absolute earnings surprises greater than $5 \%$ are also excluded. The final sample consists of 141,328 quarterly earnings announcements of NYSE/AMEX/NASDAQ firms from 1985 to 2007 with the data necessary to calculate ESURP and RET. Panel A reports the means and standard deviations. Panel B reports the Pearson correlations.

\begin{tabular}{|c|c|c|c|c|c|c|c|c|c|c|c|}
\hline & $R E T$ & ESURP & GOOD & EGSPEC & SSPEC & $M / B$ & BETA & BOND30 & LogSIZE & $A B V O L$ & IO \\
\hline & \multicolumn{11}{|c|}{ Panel A: Means and Standard Deviations } \\
\hline Mean & 0.004 & -0.001 & 0.542 & 0.161 & 0.018 & 2.987 & 0.960 & 6.247 & 6.524 & 0.264 & 49.877 \\
\hline \multirow[t]{2}{*}{ Standard deviation } & 0.079 & 0.009 & 0.498 & 0.673 & 0.109 & 2.512 & 0.557 & 1.417 & 1.720 & 0.558 & 23.849 \\
\hline & \multicolumn{11}{|c|}{ Panel B: Cross-sectional Correlations } \\
\hline RET & & 0.154 & 0.195 & -0.018 & 0.002 & -0.003 & -0.004 & -0.012 & 0.000 & 0.014 & 0.015 \\
\hline ESURP & & & 0.571 & -0.334 & 0.094 & 0.028 & -0.026 & -0.008 & 0.056 & 0.019 & 0.030 \\
\hline GOOD & & & & -0.207 & 0.077 & 0.046 & -0.015 & -0.038 & 0.035 & 0.015 & 0.040 \\
\hline NEGSPEC & & & & & -0.040 & 0.071 & 0.072 & -0.071 & 0.022 & 0.031 & 0.043 \\
\hline POSSPEC & & & & & & 0.002 & 0.012 & -0.023 & 0.036 & 0.019 & 0.034 \\
\hline$M / B$ & & & & & & & 0.190 & -0.125 & 0.196 & 0.117 & 0.044 \\
\hline BETA & & & & & & & & -0.097 & 0.174 & 0.247 & 0.225 \\
\hline BOND30 & & & & & & & & & -0.209 & -0.203 & -0.316 \\
\hline LogSIZE & & & & & & & & & & 0.103 & 0.473 \\
\hline$A B V O L$ & & & & & & & & & & & 0.245 \\
\hline
\end{tabular}




\section{Table 3}

\section{Asymmetric Price Reactions to Earnings Surprises: Effects of Abnormal Trading Volume}

$R E T=\beta_{0}+\beta_{1} G O O D+\beta_{2} E S U R P+\beta_{3} E S U R P \times G O O D+\gamma_{1} E S U R P \times|E S U R P|+\gamma_{2} E S U R P \times N E G S P E C+\gamma_{3} E S U R P \times P O S S P E C+\gamma_{4} E S U R P \times M / B+\gamma_{5} E S U R P \times B E T A$
$+\gamma_{6} E S U R P \times B O N D 30+\gamma_{7} E S U R P \times L O g S I Z E$

The regression variables are defined in Table 2 . We sort the samples into three groups based on abnormal trading volume $(A B V O L)$ by each year-quarter. Low, Medium, and High represent stocks in the bottom 30\%, middle $40 \%$, and top $30 \%$ of the distribution, respectively. Within each $A B V O L$ group, we form portfolios of the individual stocks by ranking earnings surprise (ESURP) into 20 portfolios. We estimate the regression separately for the low-, medium-, and high- $A B V O L$ groups, defining RET as the average return and ESURP as the average earnings surprise of all stocks in each earnings surprise portfolio. The dummy variable, GOOD, is coded as one if ESURP is positive and coded as zero if negative. Similarly, all of the control variables are defined as the average value in each earnings surprise portfolio. To mitigate the influence of extreme values, we truncate $M / B$ and $B E T A$ at the $1 \%$ and 99\% level. We truncate NEGSPEC and POSSPEC at the 99\% level. The full sample consists of 141,328 quarterly earnings announcements of NYSE/AMEX/NASDAQ firms from 1985 to 2007 with the data necessary to calculate ESURP and RET. Stocks priced below one dollar are excluded. Zero earnings surprises and price-deflated absolute earnings surprises greater than 5\% are also excluded. Following Petersen (2009), we calculate the tstatistics using clustered (by time) standard errors to account for the cross-sectional residual dependence within each year-quarter. $T$ statistics are reported in parentheses. $*{ }^{* *}$, and $* * *$ indicate significance at the $10 \%, 5 \%$, and $1 \%$ levels, respectively.

\begin{tabular}{|c|c|c|c|c|c|c|c|c|c|c|c|c|c|}
\hline & $\beta_{0}$ & $\beta_{1}$ & $\beta_{2}$ & $\beta_{3}$ & $\gamma_{1}$ & $\gamma_{2}$ & $\gamma_{3}$ & $\gamma_{4}$ & $\gamma_{5}$ & $\gamma_{6}$ & $\gamma_{7}$ & $\begin{array}{c}\text { Sample } \\
\text { size }\end{array}$ & $\begin{array}{l}\text { Adj.-R }{ }^{2} \\
(\%)\end{array}$ \\
\hline Full Sample & $\begin{array}{r}* * *-0.010 \\
(-18.17)\end{array}$ & $\begin{array}{r}* * * 0.023 \\
(28.91)\end{array}$ & $\begin{array}{r}* * * 0.367 \\
(5.59)\end{array}$ & $\begin{array}{r}* * * 0.777 \\
(7.70)\end{array}$ & & & & & & & & 1840 & 64.47 \\
\hline Full Sample & $\begin{array}{r}* * *_{-} 0.005 \\
(-10.50)\end{array}$ & $\begin{array}{r}* * * 0.015 \\
(20.25)\end{array}$ & $\begin{array}{r}* * * 2.016 \\
(3.27)\end{array}$ & $\begin{array}{c}* * 0.458 \\
(2.47)\end{array}$ & $\begin{array}{r}* * *-5.044 \\
(-7.95)\end{array}$ & $\begin{array}{r}{ }_{-}-0.207 \\
(-1.72)\end{array}$ & $\begin{array}{r}* * *-4.979 \\
(-2.68)\end{array}$ & $\begin{array}{l}* 0.229 \\
(1.89)\end{array}$ & $\begin{array}{l}-0.334 \\
(-1.34)\end{array}$ & $\begin{array}{r}-0.037 \\
(-0.94)\end{array}$ & $\begin{array}{l}0.084 \\
(1.06)\end{array}$ & 1840 & 68.46 \\
\hline Low $A B V O L$ & $\begin{array}{r}* * *_{-} 0.004 \\
(-7.47)\end{array}$ & $\begin{array}{r}* * * 0.007 \\
(7.36)\end{array}$ & $\begin{array}{r}* * * 1.471 \\
(2.86)\end{array}$ & $\begin{array}{r}* * *_{-} 0.529 \\
(-3.58)\end{array}$ & $\begin{array}{r}* * *-2.403 \\
(-3.41)\end{array}$ & $\begin{array}{l}-0.150 \\
(-1.60)\end{array}$ & $\begin{array}{r}0.074 \\
(0.05)\end{array}$ & $\begin{array}{l}-0.029 \\
(-0.38)\end{array}$ & $\begin{array}{l}-0.007 \\
(-0.03)\end{array}$ & $\begin{array}{l}-0.014 \\
(-0.40)\end{array}$ & $\begin{array}{l}-0.004 \\
(-0.05)\end{array}$ & 1840 & 27.30 \\
\hline Med. $A B V O L$ & $\begin{array}{r}* *-0.001 \\
(-2.28)\end{array}$ & $\begin{array}{r}* * * 0.012 \\
(13.55)\end{array}$ & $\begin{array}{r}0.717 \\
(1.20)\end{array}$ & $\begin{array}{l}-0.096 \\
(-0.57)\end{array}$ & $\begin{array}{r}* * *-2.598 \\
(-3.76)\end{array}$ & $\begin{array}{r}* *-0.267 \\
(-1.90)\end{array}$ & $\begin{array}{l}-0.846 \\
(-0.55)\end{array}$ & $\begin{array}{r}* * * 0.331 \\
(3.23)\end{array}$ & $\begin{array}{r}-0.053 \\
(-0.16)\end{array}$ & $\begin{array}{l}-0.020 \\
(-0.50)\end{array}$ & $\begin{array}{l}0.076 \\
(0.80)\end{array}$ & 1840 & 50.85 \\
\hline High $A B V O L$ & $\begin{array}{r}* * *-0.014 \\
(-8.08)\end{array}$ & $\begin{array}{r}* * * 0.032 \\
(14.60)\end{array}$ & $\begin{array}{r}1.143 \\
(0.86)\end{array}$ & $\begin{array}{r}* * * 1.295 \\
(3.94)\end{array}$ & $\begin{array}{r}* * *-7.269 \\
(-6.67)\end{array}$ & $\begin{array}{r}* *-0.413 \\
(-2.22)\end{array}$ & $\begin{array}{r}* *-3.980 \\
(-2.05)\end{array}$ & $\begin{array}{r}* * 0.362 \\
(2.25)\end{array}$ & $\begin{array}{r}{ }^{*}-0.259 \\
(-0.61)\end{array}$ & $\begin{array}{l}-0.102 \\
(-1.34)\end{array}$ & $\begin{array}{r}* * 0.445 \\
(2.41)\end{array}$ & 1840 & 56.26 \\
\hline High - Low & & & & $\begin{array}{r}* * * 1.824 \\
(4.85)\end{array}$ & & & & & & & & & \\
\hline
\end{tabular}




\section{Table 4}

\section{Asymmetric Price Reactions to Earnings Surprises: Joint Effects of Abnormal Trading Volume and Institutional Ownership}

$R E T=\beta_{0}+\beta_{1} G O O D+\beta_{2} E S U R P+\beta_{3} E S U R P \times G O O D+\gamma_{1} E S U R P \times|E S U R P|+\gamma_{2} E S U R P \times N E G S P E C+\gamma_{3} E S U R P \times P O S S P E C+\gamma_{4} E S U R P \times M / B+\gamma_{5} E S U R P \times B E T A$ $+\gamma_{6} E S U R P \times B O N D 30+\gamma_{7} E S U R P \times \operatorname{LogSIZE}$

The regression variables are defined in Table 2. We first sort the samples into three groups based on institutional ownership (IO) in each year-quarter. Within each institutional ownership group, we further sort the samples into three groups based on abnormal trading volume (ABVOL). Low, Medium, and High represent stocks in the bottom $30 \%$, middle $40 \%$, and top $30 \%$ of the distribution, respectively. Within each $I O$ and $A B V O L$ group, we form portfolios of the individual stocks by ranking earnings surprise (ESURP) into 20 portfolios. We estimate the regression separately for the low-, medium-, and high- $A B V O L$ groups within each $I O$ group, defining $R E T$ as the average return and ESURP as the average earnings surprise of all stocks in each earnings surprise portfolio. The dummy variable, GOOD, is coded as one if ESURP is positive and coded as zero if negative. Similarly, all of the control variables are defined as the average value in each earnings surprise portfolio. To mitigate the influence of extreme values, we truncate $M / B$ and $B E T A$ at the $1 \%$ and $99 \%$ level. We truncate NEGSPEC and POSSPEC at the $99 \%$ level. The full sample consists of 141,328 quarterly earnings announcements of NYSE/AMEX/NASDAQ firms from 1985 to 2007 with the data necessary to calculate ESURP and RET. Stocks priced below one dollar are excluded. Zero earnings surprises and price-deflated absolute earnings surprises greater than 5\% are also excluded. Following Petersen (2009), we calculate the tstatistics using clustered (by time) standard errors to account for the cross-sectional residual dependence within each year-quarter. $T$ statistics are reported in parentheses. *, **, and $* * *$ indicate significance at the $10 \%, 5 \%$, and $1 \%$ levels, respectively. 


\begin{tabular}{|c|c|c|c|c|c|c|c|c|c|c|c|c|c|c|}
\hline & & $\beta_{0}$ & $\beta_{1}$ & $\beta_{2}$ & $\beta_{3}$ & $\gamma_{1}$ & $\gamma_{2}$ & $\gamma_{3}$ & $\gamma_{4}$ & $\gamma_{5}$ & $\gamma_{6}$ & $\gamma_{7}$ & $\begin{array}{c}\text { Sample } \\
\text { Size }\end{array}$ & $\begin{array}{c}\text { Adj.- } \mathrm{R}^{2} \\
(\%)\end{array}$ \\
\hline \multirow{3}{*}{ High IO } & Low $A B V O L$ & $\begin{array}{r}* * *-0.002 \\
(-2.95)\end{array}$ & $\begin{array}{r}* * * 0.008 \\
(7.38)\end{array}$ & $\begin{array}{l}0.406 \\
(0.41)\end{array}$ & $\begin{array}{l}-0.227 \\
(-0.93)\end{array}$ & $\begin{array}{r}-0.614 \\
(-1.00)\end{array}$ & $\begin{array}{r}* *-0.215 \\
(-2.37)\end{array}$ & $\begin{array}{r}0.742 \\
(0.97)\end{array}$ & $\begin{array}{r}* * 0.268 \\
(2.30)\end{array}$ & $\begin{array}{r}0.179 \\
(0.64)\end{array}$ & $\begin{array}{l}0.030 \\
(0.54)\end{array}$ & $\begin{array}{c}-0.107 \\
(-0.80)\end{array}$ & 1840 & 10.80 \\
\hline & Med. ABVOL & $\begin{array}{r}* *-0.002 \\
(-1.56)\end{array}$ & $\begin{array}{r}* * * 0.016 \\
(9.48)\end{array}$ & $\begin{array}{r}* * * 4.872 \\
(3.60)\end{array}$ & $\begin{array}{l}0.166 \\
(0.65)\end{array}$ & $\begin{array}{r}* *-1.192 \\
(-2.18)\end{array}$ & $\begin{array}{l}-0.064 \\
(-0.38)\end{array}$ & $\begin{array}{l}0.093 \\
(0.08)\end{array}$ & $\begin{array}{l}-0.219 \\
(-0.97)\end{array}$ & $\begin{array}{l}-0.154 \\
(-0.43)\end{array}$ & $\begin{array}{r}* *_{-} 0.151 \\
(-2.10)\end{array}$ & $\begin{array}{r}* *_{-} 0.370 \\
(-2.28)\end{array}$ & 1840 & 22.49 \\
\hline & $\begin{array}{l}\text { High } A B V O L \\
\text { High - Low }\end{array}$ & $\begin{array}{r}* * *-0.018 \\
(-8.96)\end{array}$ & $\begin{array}{r}* * * 0.034 \\
(10.13)\end{array}$ & $\begin{array}{r}* * * 6.057 \\
(2.74)\end{array}$ & $\begin{array}{l}0.690 \\
(0.98) \\
0.917 \\
(1.19) \\
\end{array}$ & $\begin{array}{r}* * *-5.342 \\
(-3.49)\end{array}$ & $\begin{array}{r}* * *-1.140 \\
(-4.34)\end{array}$ & $\begin{array}{l}0.113 \\
(0.05)\end{array}$ & $\begin{array}{r}* * * 0.621 \\
(3.63)\end{array}$ & $\begin{array}{l}0.268 \\
(0.38)\end{array}$ & $\begin{array}{r}* *-0.220 \\
(-2.33)\end{array}$ & $\begin{array}{r}-0.310 \\
(-0.76)\end{array}$ & 1840 & 32.42 \\
\hline \multirow{3}{*}{ Med. IO } & Low $A B V O L$ & $\begin{array}{r}* * *-0.004 \\
(-4.19)\end{array}$ & $\begin{array}{r}* * * 0.006 \\
(4.71)\end{array}$ & $\begin{array}{r}* * * 2.643 \\
(3.37)\end{array}$ & $\begin{array}{r}-0.173 \\
(-0.82)\end{array}$ & $\begin{array}{r}* * *-2.028 \\
(-4.03)\end{array}$ & $\begin{array}{r}* * *_{-} 0.277 \\
(-2.90)\end{array}$ & $\begin{array}{r}* *-1.931 \\
(-2.31)\end{array}$ & $\begin{array}{l}0.088 \\
(0.70)\end{array}$ & $\begin{array}{r}0.092 \\
(0.16)\end{array}$ & $\begin{array}{r}-0.040 \\
(-0.56)\end{array}$ & $\begin{array}{r}* *-0.217 \\
(-2.08)\end{array}$ & 1840 & 17.17 \\
\hline & Med. ABVOL & $\begin{array}{r}* *-0.002 \\
(-2.42)\end{array}$ & $\begin{array}{r}* * * 0.013 \\
(11.12)\end{array}$ & $\begin{array}{r}* * * 2.957 \\
(3.42)\end{array}$ & $\begin{array}{l}-0.133 \\
(-0.59)\end{array}$ & $\begin{array}{r}* * *-2.689 \\
(-3.57)\end{array}$ & $\begin{array}{l}-0.224 \\
(-1.47)\end{array}$ & $\begin{array}{r}0.717 \\
(0.44)\end{array}$ & $\begin{array}{r}0.048 \\
(0.44)\end{array}$ & $\begin{array}{l}-0.475 \\
(-1.50)\end{array}$ & $\begin{array}{r}* *-0.112 \\
(-2.05)\end{array}$ & $\begin{array}{l}-0.046 \\
(-0.44)\end{array}$ & 1840 & 32.08 \\
\hline & $\begin{array}{l}\text { High } A B V O L \\
\text { High - Low }\end{array}$ & $\begin{array}{r}* * *-0.016 \\
(-6.45)\end{array}$ & $\begin{array}{r}* * * 0.036 \\
(11.24)\end{array}$ & $\begin{array}{r}2.563 \\
(1.52)\end{array}$ & $\begin{array}{r}* * * 1.036 \\
(2.85) \\
* * * 1.208 \\
(3.02) \\
\end{array}$ & $\begin{array}{r}* * *-7.246 \\
(-5.57)\end{array}$ & $\begin{array}{l}0.008 \\
(0.04)\end{array}$ & $\begin{array}{r}-1.110 \\
(-0.68)\end{array}$ & $\begin{array}{l}0.108 \\
(0.68)\end{array}$ & $\begin{array}{l}-0.711 \\
(-1.43)\end{array}$ & $\begin{array}{r}-0.063 \\
(-0.55)\end{array}$ & $\begin{array}{l}0.275 \\
(1.29)\end{array}$ & 1840 & 37.98 \\
\hline \multirow{4}{*}{ Low IO } & Low $A B V O L$ & $\begin{array}{r}* * *-0.007 \\
(-6.48)\end{array}$ & $\begin{array}{r}* * * 0.007 \\
(4.89)\end{array}$ & $\begin{array}{l}0.231 \\
(0.36)\end{array}$ & $\begin{array}{r}* * *-0.513 \\
(-2.86)\end{array}$ & $\begin{array}{r}* * *-2.391 \\
(-3.92)\end{array}$ & $\begin{array}{l}0.036 \\
(0.43)\end{array}$ & $\begin{array}{r}-2.129 \\
(-1.52)\end{array}$ & $\begin{array}{l}-0.075 \\
(-1.51)\end{array}$ & $\begin{array}{l}0.131 \\
(0.89)\end{array}$ & $\begin{array}{l}0.022 \\
(0.53)\end{array}$ & $\begin{array}{l}0.153 \\
(1.29)\end{array}$ & 1840 & 8.42 \\
\hline & Med. $A B V O L$ & $\begin{array}{r}* * *-0.004 \\
(-4.40)\end{array}$ & $\begin{array}{r}* * * 0.013 \\
(7.83)\end{array}$ & $\begin{array}{l}0.789 \\
(1.29)\end{array}$ & $\begin{array}{l}-0.166 \\
(-0.83)\end{array}$ & $\begin{array}{r}* *-1.927 \\
(-2.56)\end{array}$ & $\begin{array}{l}-0.026 \\
(-0.19)\end{array}$ & $\begin{array}{r}0.595 \\
(0.37)\end{array}$ & $\begin{array}{l}0.106 \\
(1.32)\end{array}$ & $\begin{array}{r}-0.315 \\
(-1.09)\end{array}$ & $\begin{array}{l}-0.041 \\
(-0.91)\end{array}$ & $\begin{array}{l}0.121 \\
(1.09)\end{array}$ & 1840 & 21.51 \\
\hline & High $A B V O L$ & $\begin{array}{r}* * *-0.014 \\
(-5.44)\end{array}$ & $\begin{array}{r}* * * 0.038 \\
(11.22)\end{array}$ & $\begin{array}{r}* * 3.131 \\
(2.33)\end{array}$ & $\begin{array}{r}* * * 1.243 \\
(3.50)\end{array}$ & $\begin{array}{r}* *-2.913 \\
(-2.16)\end{array}$ & $\begin{array}{l}-0.217 \\
(-1.03)\end{array}$ & $\begin{array}{r}* * *-4.487 \\
(-3.75)\end{array}$ & $\begin{array}{r}* * 0.277 \\
(2.08)\end{array}$ & $\begin{array}{r}* *-0.858 \\
(-2.12)\end{array}$ & $\begin{array}{r}*-0.203 \\
(-1.97)\end{array}$ & $\begin{array}{l}0.010 \\
(0.05)\end{array}$ & 1840 & 33.25 \\
\hline & High - Low & & & & $\begin{array}{r}* * * 1.756 \\
(4.64)\end{array}$ & & & & & & & & & \\
\hline
\end{tabular}


Table 5

\section{Abnormal Returns around Quarterly Earnings Announcements}

This table reports the average abnormal returns (RET) around the quarterly earnings announcements for the portfolios formed using proxies for differences of opinion and institutional ownership (IO). RET is the three-day, $[-1,1]$, return around quarterly earnings announcements adjusted by the CRSP value-weighted market return. Panel A shows the mean abnormal returns around the quarterly earnings announcements for the portfolios formed using TURN alone, as well as the portfolios formed using both TURN and $I O$ (more specifically, the stocks are first sorted by $I O$ for each year-quarter and then within each $I O$ portfolio further sorted into TURN portfolios). Low, Medium, and High represent stocks in the bottom 30\%, middle 40\%, and top $30 \%$ of the distribution, respectively. TURN is the average turnover from trading day -55 to trading day -11 relative to the earnings announcement, the proxy used for differences of opinion prior to earnings announcements in Berkman et al. (2009). Panel B performs the same analysis as Panel A, except that we use $A B V O L$, a proxy for differential interpretations of earnings announcements, to replace TURN. Abnormal trading volume (ABVOL) is the average turnover over $[-1,+1]$ minus the average turnover over $[-55,-11]$ relative to the earnings announcements. Panel $C$ reports the mean abnormal returns around the quarterly earnings announcements for portfolios independently sorted into low, medium, and high groups based on TURN and $A B V O L$. To be consistent with Berkman et al. (2009), we restrict the sample to firm-quarters in the period from 1985 to 2005 with earnings announcement dates and stock return information available. We exclude firms in financial industries (SIC Codes 6000 to 6999) and regulated industries (SIC Codes 4900 to 4999). We further exclude the earnings announcements of firms with $\$ 10$ million or less in total assets, $\$ 10$ million or less in the market value of equity, and those with a price of less than $\$ 1$ per share, as reported on COMPUSTAT, at the start of the current fiscal quarter. The final sample consists of 274,529 firm-quarters. $*, * *$, and $* * *$ indicate significance at the $10 \%, 5 \%$, and $1 \%$ levels, respectively.

\begin{tabular}{|c|c|c|c|c|c|c|c|c|}
\hline \multicolumn{9}{|c|}{ Panel A: Dependent Sorts on IO and TURN(-55, -11) } \\
\hline & \multicolumn{2}{|c|}{ Low TURN } & \multicolumn{2}{|c|}{ Med. TURN } & \multicolumn{2}{|c|}{ High TURN } & \multicolumn{2}{|c|}{ High - Low } \\
\hline & $\begin{array}{c}\text { Ave Obs Per } \\
\text { Quarter }\end{array}$ & RET & $\begin{array}{c}\text { Ave Obs Per } \\
\text { Quarter }\end{array}$ & RET & $\begin{array}{c}\text { Ave Obs Per } \\
\text { Quarter }\end{array}$ & RET & RET & t-stat \\
\hline Full Sample & 980 & $0.57 \%$ & 1307 & $0.12 \%$ & 980 & $-0.12 \%$ & $* * *_{-} 0.69 \%$ & -10.45 \\
\hline High $I O$ & 289 & $0.38 \%$ & 386 & $0.35 \%$ & 289 & $0.35 \%$ & $-0.03 \%$ & -0.37 \\
\hline Med IO & 385 & $0.52 \%$ & 515 & $0.13 \%$ & 385 & $-0.24 \%$ & $* * *-0.76 \%$ & -9.06 \\
\hline Low IO & 289 & $0.92 \%$ & 386 & $0.13 \%$ & 289 & $-0.86 \%$ & $* * *-1.78 \%$ & -15.81 \\
\hline \multicolumn{9}{|c|}{ Panel B: Dependent Sorts on $I O$ and $A B V O L(-1,+1)$} \\
\hline & \multicolumn{2}{|c|}{ Low $A B V O L$} & \multicolumn{2}{|c|}{ Med. $A B V O L$} & \multicolumn{2}{|c|}{ High $A B V O L$} & \multicolumn{2}{|c|}{ High - Low } \\
\hline & $\begin{array}{c}\text { Ave Obs Per } \\
\text { Quarter }\end{array}$ & RET & $\begin{array}{c}\text { Ave Obs Per } \\
\text { Quarter }\end{array}$ & $R E T$ & $\begin{array}{c}\text { Ave Obs Per } \\
\text { Quarter }\end{array}$ & RET & RET & t-stat \\
\hline Full Sample & 980 & $-0.67 \%$ & 1307 & $0.12 \%$ & 980 & $1.12 \%$ & $* * * 1.78 \%$ & 15.11 \\
\hline High $I O$ & 289 & $-0.06 \%$ & 386 & $0.63 \%$ & 289 & $0.44 \%$ & $* * * 0.50 \%$ & 3.53 \\
\hline Med IO & 385 & $-0.61 \%$ & 515 & $0.12 \%$ & 385 & $0.91 \%$ & $* * * 1.52 \%$ & 10.47 \\
\hline Low IO & 289 & $-1.24 \%$ & 386 & $-0.34 \%$ & 289 & $1.94 \%$ & $* * * 3.18 \%$ & 20.80 \\
\hline
\end{tabular}




\begin{tabular}{|c|c|c|c|c|c|c|c|c|}
\hline \multicolumn{9}{|c|}{ Panel C: Independent Sorts on TURN $(-55,-11)$ and ABVOL $(-1,+1)$} \\
\hline & \multicolumn{2}{|c|}{ Low $A B V O L$} & \multicolumn{2}{|c|}{ Med. $A B V O L$} & \multicolumn{2}{|c|}{ High $A B V O L$} & \multicolumn{2}{|c|}{ High - Low } \\
\hline & $\begin{array}{c}\text { Ave Obs Per } \\
\text { Quarter }\end{array}$ & $R E T$ & $\begin{array}{c}\text { Ave Obs Per } \\
\text { Quarter }\end{array}$ & $R E T$ & $\begin{array}{c}\text { Ave Obs Per } \\
\text { Quarter }\end{array}$ & $R E T$ & $R E T$ & t-stat \\
\hline Full Sample & 980 & $-0.67 \%$ & 1307 & $0.12 \%$ & 980 & $1.12 \%$ & $* * * 1.78 \%$ & 15.11 \\
\hline High TURN & 369 & $-0.76 \%$ & 171 & $0.09 \%$ & 440 & $0.34 \%$ & $* * * 1.21 \%$ & 9.09 \\
\hline Med TURN & 411 & $-0.65 \%$ & 499 & $0.04 \%$ & 397 & $1.01 \%$ & $* * * 1.66 \%$ & 12.79 \\
\hline Low TURN & 199 & $-0.52 \%$ & 637 & $0.19 \%$ & 143 & $3.80 \%$ & $* * * 5.35 \%$ & 17.21 \\
\hline
\end{tabular}




\section{Table 6}

\section{Post-Earnings-Announcement Drift: Joint Effects of Abnormal Trading Volume and Institutional Ownership}

This table reports the mean abnormal returns (RET60) for the decile portfolios formed on the basis of price-scaled earnings surprises (ESURP). RET60 is the 60-day return, $[+2,+61]$, around the quarterly earnings announcements adjusted for returns of NYSE/AMEX/NASDAQ firms of the same size decile. ESURP is the difference between firm reported quarterly earnings per share (EPS) before extraordinary items and the consensus analyst forecast scaled by the stock price at the fiscal quarter-end. Consensus analyst forecast is the median analyst forecasts made within 60 days prior to the earnings announcement date. Panel A forms earnings surprise portfolios within the subsamples sorted by abnormal trading volume $(A B V O L)$ in each year-quarter. Panel B forms earnings surprise portfolios within the subsamples first sorted by institutional ownership (IO) and then by abnormal trading volume $(A B V O L)$ in each year-quarter. Abnormal trading volume $(A B V O L)$ is the average turnover over $[-1,+1]$ minus the average turnover over $[-55,-11]$ relative to the earnings announcements. Turnover is trading volume divided by shares outstanding, multiplied by 0.5 for NASDAQ stocks. IO is the last reported percentage of shares outstanding held by institutional investors within 180 days prior to the earnings announcements. Low, Medium, and High represent stocks in the bottom $30 \%$, middle $40 \%$, and top $30 \%$ of the distribution, respectively. Stocks priced below $\$ 1$ are excluded. Zero earnings surprises and price-deflated absolute earnings surprises greater than $5 \%$ are also excluded. The final sample consists of 141,328 quarterly earnings announcements of NYSE/AMEX/NASDAQ firms from 1985 to 2007 with the data necessary to calculate ESURP and RET. *, **, and *** indicate significance at the $10 \%, 5 \%$, and $1 \%$ levels, respectively.

\begin{tabular}{|c|c|c|c|c|c|c|c|c|c|c|c|c|}
\hline \multicolumn{13}{|c|}{ Panel A: Sort on Abnormal Trading Volume (ABVOL) } \\
\hline & \multicolumn{4}{|c|}{ Low $A B V O L$} & \multicolumn{4}{|c|}{ Med. $A B V O L$} & \multicolumn{4}{|c|}{ High $A B V O L$} \\
\hline & D1 & D10 & $\begin{array}{l}\text { Hedge Return } \\
\text { (D10-D1) }\end{array}$ & $\begin{array}{c}\text { Hedge Return } \\
\text { (\% from long } \\
\text { position) }\end{array}$ & D1 & D10 & $\begin{array}{l}\text { Hedge Return } \\
\text { (D10-D1) }\end{array}$ & $\begin{array}{c}\text { Hedge Return } \\
\text { (\% from long } \\
\text { position) }\end{array}$ & D1 & D10 & $\begin{array}{l}\text { Hedge Return } \\
\text { (D10-D1) }\end{array}$ & $\begin{array}{c}\text { Hedge Return } \\
\text { (\% from long } \\
\text { position) }\end{array}$ \\
\hline Full Sample & -2.57 & 0.08 & $* * * 2.65$ & $3 \%$ & -2.05 & 2.48 & $* * * 4.53$ & $55 \%$ & -0.93 & 4.98 & $* * * 5.91$ & $84 \%$ \\
\hline
\end{tabular}

Panel B: Sort on Institutional Ownership (IO) and Abnormal Trading Volume (ABVOL)

\begin{tabular}{|c|c|c|c|c|c|c|c|c|c|c|c|c|}
\hline & \multicolumn{4}{|c|}{ Low $A B V O L$} & \multicolumn{4}{|c|}{ Med. ABVOL } & \multicolumn{4}{|c|}{ High $A B V O L$} \\
\hline & D1 & D10 & $\begin{array}{l}\text { Hedge Return } \\
\text { (D10-D1) }\end{array}$ & $\begin{array}{l}\text { Hedge Return } \\
\text { (\% from long } \\
\text { position) }\end{array}$ & D1 & D10 & $\begin{array}{l}\text { Hedge Return } \\
\text { (D10-D1) }\end{array}$ & $\begin{array}{l}\text { Hedge Return } \\
\text { (\% from long } \\
\text { position) }\end{array}$ & D1 & D10 & $\begin{array}{l}\text { Hedge Return } \\
\text { (D10-D1) }\end{array}$ & $\begin{array}{c}\text { Hedge Return } \\
\text { (\% from long } \\
\text { position) }\end{array}$ \\
\hline High IO & -2.05 & 0.23 & $* * * 2.28$ & $10 \%$ & -0.42 & 2.33 & $* * * 2.75$ & $85 \%$ & -1.23 & 2.56 & $* * * 3.79$ & $68 \%$ \\
\hline Med. IO & -2.29 & 0.18 & $* * * 2.47$ & $7 \%$ & -1.00 & 2.09 & ***3.09 & $68 \%$ & 0.29 & 4.16 & $* * * 3.87$ & $107 \%$ \\
\hline Low $I O$ & -2.37 & 0.24 & $* 2.62$ & $9 \%$ & -3.11 & 1.51 & $* * * 4.61$ & $33 \%$ & -3.44 & 6.69 & $* * * 10.13$ & $66 \%$ \\
\hline
\end{tabular}

